ARTICLE

DOI: $10.1038 / \mathrm{s} 41467-018-06681-5$

\title{
Characterization of a long overlooked copper protein from methane- and ammonia-oxidizing bacteria
}

Oriana S. Fisher ${ }^{1}$, Grace E. Kenney (10 ${ }^{1}$, Matthew O. Ross ${ }^{1}$, Soo Y. Ro ${ }^{1}$, Betelehem E. Lemma1, Sharon Batelu², Paul M. Thomas (1) ${ }^{1}$, Victoria C. Sosnowski ${ }^{1}$, Caroline J. DeHart ${ }^{1}$, Neil L. Kelleher (1) ${ }^{1}$, Timothy L. Stemmler ${ }^{2}$, Brian M. Hoffman ${ }^{1} \&$ Amy C. Rosenzweig (i) ${ }^{1}$

Methane-oxidizing microbes catalyze the oxidation of the greenhouse gas methane using the copper-dependent enzyme particulate methane monooxygenase (pMMO). Isolated pMMO exhibits lower activity than whole cells, however, suggesting that additional components may be required. A pMMO homolog, ammonia monooxygenase (AMO), converts ammonia to hydroxylamine in ammonia-oxidizing bacteria (AOB) which produce another potent greenhouse gas, nitrous oxide. Here we show that $P$ moD, a protein encoded within many pmo operons that is homologous to the AmoD proteins encoded within $A O B$ amo operons, forms a copper center that exhibits the features of a well-defined $\mathrm{Cu}_{\mathrm{A}}$ site using a previously unobserved ligand set derived from a cupredoxin homodimer. PmoD is critical for copperdependent growth on methane, and genetic analyses strongly support a role directly related to $\mathrm{pMMO}$ and $\mathrm{AMO}$. These findings identify a copper-binding protein that may represent a missing link in the function of enzymes critical to the global carbon and nitrogen cycles.

\footnotetext{
${ }^{1}$ Departments of Molecular Biosciences and Chemistry, Northwestern University, Evanston 60208 IL, USA. ${ }^{2}$ Department of Pharmaceutical Sciences, Wayne State University, Detroit 48201 MI, USA. Correspondence and requests for materials should be addressed to A.C.R. (email: amyr@northwestern.edu)
} 
$\mathrm{M}$ ethane-oxidizing microbes ${ }^{1}$ are nature's primary sink for methane, which is the second most abundant greenhouse gas and has a global warming potential $\sim 84$ times that of $\mathrm{CO}_{2}$ over a 20 -year period ${ }^{2}$. The first metabolic step carried out by methane-oxidizing bacteria (MOB), the oxidation of methane to methanol, is catalyzed by methane monooxygenase (MMO) enzymes ${ }^{3}$. Understanding how MMOs break a $105 \mathrm{kcal}$ mol $^{-14}$ methane C-H bond is central to efforts to develop biological gas-to-liquid technologies 5 . The primary MMO in nature is particulate MMO (pMMO), a copper-dependent, integral membrane enzyme composed of three subunits, PmoB, PmoA, and $\mathrm{PmoC}^{3,5}$. A pMMO homolog, ammonia monooxygenase (AMO), converts ammonia to hydroxylamine in ammoniaoxidizing bacteria $(\mathrm{AOB})^{6}$ which produce another potent greenhouse gas, nitrous oxide ${ }^{7}$.

Studies of pMMO and AMO have been hindered for the past 30 years by low enzymatic activity upon isolation. pMMO activity decreases 10 - to 100 -fold upon membrane isolation and protein purification $^{3}$, and a purified AMO sample with enzymatic activity has never been obtained ${ }^{8}$. The persistent difficulties in obtaining high-activity $\mathrm{pMMO} / \mathrm{AMO}$ preparations may be due to the absence of unidentified protein components that facilitate loading, assembly, and stabilization of the active sites and/or delivery of electrons and protons. Additional genes encoded by the pmo and $a m o$ operons provide potential candidates for such missing links. In alpha-proteobacterial MOB ( $\alpha-\mathrm{MOB})$, including the Methylosinus and Methylocystis genera, and in betaproteobacterial $\mathrm{AOB}(\beta-\mathrm{AOB})$, including the Nitrosomonas, Nitrosospira, and Nitrosovibrio genera ${ }^{9}$, the gene denoted pmoD/ $a m o D$ is adjacent to the genes encoding the three $\mathrm{pMMO} / \mathrm{AMO}$ enzyme subunits (Fig. 1a), and is partially co-regulated with pmoCAB and $a m o C A B^{10-12}$. In beta-proteobacterial amo operons, an additional gene homologous to $a m o D$, denoted $a m o E /$ orf4, precedes amoD (Fig. 1a) ${ }^{9}$. These extended operons also encode CopC, $\mathrm{CopD}$, and sometimes $\mathrm{PCu}_{\mathrm{A}} \mathrm{C}$ proteins, all of which have been implicated in copper homeostasis in a range of bacteria ${ }^{10}$. Gamma-proteobacterial pmolamo operons contain fewer genes: in Nitrosococcus genera, only amoD follows amoCAB, and in related gamma-proteobacterial methanotrophs, including the Methylococcus genera, $p m o D$ genes are present, but are not found in pmo operons ${ }^{11,13}$. Most MOB and AOB genomes contain at least two pmoD/amoD homologs, including those of MOB from the verrucomicrobial and NC-10 subgroups and AOB belonging to the Nitrospirae phylum, although not archaeal ammonia oxidizers. Here we show that PmoD forms a copper center exhibiting the features of a $\mathrm{Cu}_{\mathrm{A}}$ site using a previously unobserved ligand set at the interface of a PmoD homodimer. We further show that PmoD is critical for the copper-dependent growth of Methylosinus trichosporium OB3b on methane. Finally, genetic analyses support a role for $\mathrm{PmoD} / \mathrm{AmoD}$ related to the function of $\mathrm{pMMO} / \mathrm{AMO}$.

\section{Results}

PmoD forms a $\mathrm{Cu}_{\mathrm{A}}$ site as a homodimer. Sequence analysis indicates that $\mathrm{PmoD} / \mathrm{AmoD}$ comprises an $\mathrm{N}$-terminal signal peptide followed by a periplasmic domain containing two strictly conserved cysteine residues and a C-terminal transmembrane helix within the inner membrane (Supplementary Figure 1a). We heterologously expressed and purified the periplasmic domain of PmoD encoded by the Methylocystis species (sp.) strain Rockwell extended pmo operon $\left(\mathrm{PmoD}_{\text {Met49242_1452; }}\right.$ there are 10 other pmoD genes in the genome of this species) (Supplementary Figure $1 \mathrm{~b}, \mathrm{~d})$. Addition of $\mathrm{CuSO}_{4}$ to $\mathrm{PmoD}_{\text {Met49242_1452 }}$ after reduction with dithiothreitol (DTT) gives rise to a species characterized by an intense purplish pink color. The absorption spectrum of this species exhibits peaks at 475,530 , and $770 \mathrm{~nm}$, resembling spectra of the $\mathrm{Cu}_{\mathrm{A}}$-containing domains of cytochrome $c$ oxidase $(\mathrm{CcO})$, nitrous oxide reductase $\left(\mathrm{N}_{2} \mathrm{OR}\right)$, and engineered $\mathrm{Cu}_{\mathrm{A}}$ proteins, including $\mathrm{Cu}_{\mathrm{A}}$ azurin ${ }^{14}$ (Fig. 1b). The copperloaded protein can be further resolved into two distinct species by size exclusion chromatography (Supplementary Figure 1c). The first of these retains the $\mathrm{Cu}_{\mathrm{A}}$-like spectral features and contains $1.4 \pm 0.2$ equivalents of $\mathrm{Cu}$ per protein molecule, while the second lacks the $\mathrm{Cu}_{\mathrm{A}}$-like spectral features and contains $3.1 \pm 1.2$ equivalents of $\mathrm{Cu}$ per protein molecule. Each was further analyzed using size exclusion chromatography with multi-angle light scattering (SEC-MALS): the $\mathrm{Cu}_{\mathrm{A}}$-like species has a molar mass of $30,540 \mathrm{Da}( \pm 2 \%)$, consistent with a PmoD ${ }_{\text {Met49242_1452 }}$ dimer, while the second species has a molar mass of $16,250 \mathrm{Da}( \pm 3 \%)$, consistent with a PmoD ${ }_{\text {Met49242_1452 }}$ monomer (Fig. 1c).

$\mathrm{Cu}_{\mathrm{A}}$ centers feature a mixed valent $\mathrm{Cu}(+1.5)-\mathrm{Cu}(+1.5)$ site in which two copper ions separated by $\sim 2.5 \AA$ are coordinated by two bridging cysteine thiolates, two in-plane histidine imidazoles, and a methionine thioether and backbone carbonyl as axial ligands. The canonical $\mathrm{Cu}_{\mathrm{A}}$ amino acid ligands derive from a conserved $\mathrm{Hx}_{34} \mathrm{Cx}_{3} \mathrm{Cx}_{3} \mathrm{Hx}_{2} \mathrm{M}$ motif ${ }^{15}$ which is not present in PmoD sequences. In typical $\mathrm{Cu}_{\mathrm{A}}$ centers, the $475 \mathrm{~nm}$ and $530 \mathrm{~nm}$ absorption maxima are assigned to sulfur (Cys) to $\mathrm{Cu}$ ligand-tometal charge transfer transitions, and the longer wavelength nearinfrared feature $(\sim 770 \mathrm{~nm})$ arises from the $\Psi \rightarrow \Psi^{\star} \mathrm{Cu}-\mathrm{Cu}$ bonding to antibonding orbital transition ${ }^{16}$. The energy of this transition is inversely correlated to the length of the $\mathrm{Cu}-\mathrm{Cu}$ bond ${ }^{14}$. In the $\mathrm{PmoD}_{\text {Met49242_1452 }}$ spectrum, this feature is blueshifted relative to natural $\mathrm{Cu}_{\mathrm{A}}$ systems $(775-808 \mathrm{~nm}$ for $\mathrm{CcO}$ and $780-800 \mathrm{~nm}$ and $\left.\mathrm{N}_{2} \mathrm{OR}\right)^{14}$ and is more similar to that observed for the semisynthetic $\mathrm{Cu}_{\mathrm{A}}$ azurin $(765 \mathrm{~nm})^{17}$, indicating that

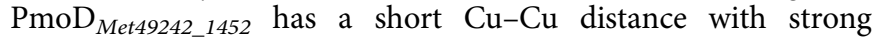
$\mathrm{Cu}-\mathrm{Cu}$ bonding. The presence of a $\mathrm{Cu}_{\mathrm{A}}$ site with a $\mathrm{Cu}_{2} \mathrm{~S}_{2}$ core is

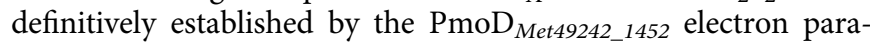
magnetic resonance (EPR) spectrum which exhibits the characteristic seven hyperfine line splitting along $g_{z}$ (Fig. 1d) ${ }^{18}$, defining a fully valence-delocalized dicopper center. However, the $A_{\mathrm{z}}$ and $g_{\mathrm{z}}$ values for the $\mathrm{PmoD}_{\text {Met49242_1452 }} \mathrm{Cu}_{\mathrm{A}}$ site $\left(A_{\mathrm{z}}=141\right.$ $\left.\mathrm{MHz}, g_{\mathrm{z}}=2.13\right)$ are significantly smaller than those of $\mathrm{Cu}_{\mathrm{A}}$ azurin $\left(A_{\mathrm{z}}=167 \mathrm{MHz}, g_{\mathrm{z}}=2.17^{19}\right)$, while compared to $\mathrm{C} c \mathrm{O}$ and $\mathrm{N}_{2} \mathrm{OR}$ $\left(A_{\mathrm{z}}=107-117 \mathrm{MHz}, g_{\mathrm{z}}=2.18, A_{\mathrm{z}}=117 \mathrm{MHz}, g_{\mathrm{z}}=2.18\right.$, respectively $)^{14}$, the $A_{\mathrm{z}}$ is larger and the $g_{\mathrm{z}}$ is smaller. The PmoD $g_{\mathrm{z}}=$ 2.13 is the smallest observed for a $\mathrm{Cu}_{\mathrm{A}}$ site to date ${ }^{14}$. By contrast, the monomeric species of $\mathrm{PmoD}_{\text {Met49242_1452 }}$ exhibits an optical spectrum with no charge transfer bands (Fig. 1c, inset) and is EPR silent. The X-ray absorption near edge structure (XANES) spectra of $\mathrm{PmoD}_{\text {Met49242_1452 }}$ exhibit features similar to those observed for $\mathrm{Cu}_{\mathrm{A}}$ model compounds and the soluble $\mathrm{Cu}_{\mathrm{A}}$ domain of Thermus thermophilus $\mathrm{CcO}^{20}$ (Fig. 1e, Supplementary Discussion). In addition, extended X-ray absorption fine structure (EXAFS) data can be fit with a $2.41 \AA \mathrm{Cu}-\mathrm{Cu}$ interaction (Supplementary Discussion, Supplementary Figure 2a-d, Supplementary Table 1), consistent with the observed absorption spectrum.

PmoD uses a non-canonical ligand set to form the $\mathrm{Cu}_{\mathrm{A}}$ site. Both the dimeric and monomeric species of $\mathrm{PmoD}_{\text {Met49242_1452 }}$ were subjected to crystallization trials, but crystals were obtained from only the monomeric form. The $1.9 \AA$ resolution structure solved by copper single wavelength anomalous dispersion (SAD) phasing (Supplementary Table 2, Supplementary Figure 3a) reveals a cupredoxin fold ${ }^{14}$ with a single copper ion located between the two PmoD ${ }_{\text {Met49242_1452 }}$ monomers in the asymmetric unit. The copper ion is coordinated in tetrahedral geometry by Met42 and Met44 from each monomer, and the two invariant cysteine residues, Cys41 and Cys65, form an intramolecular 
a
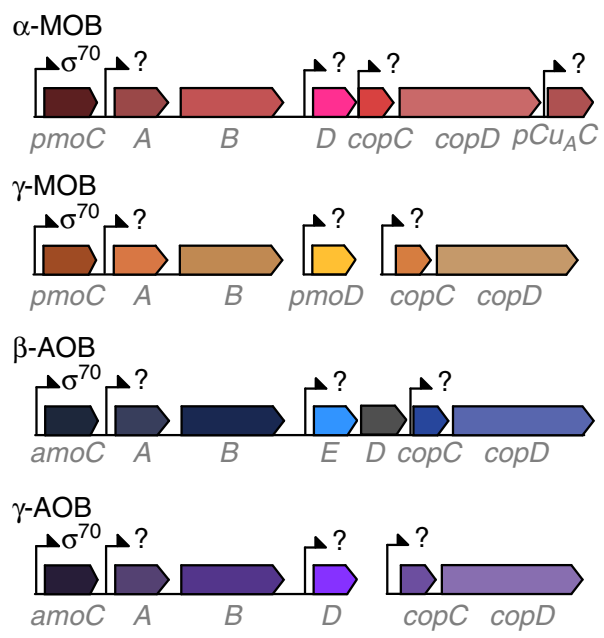

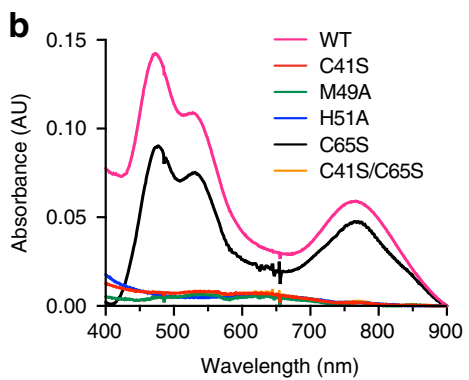

d

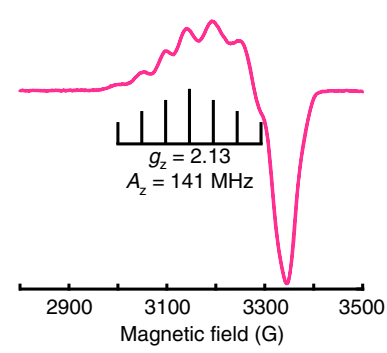

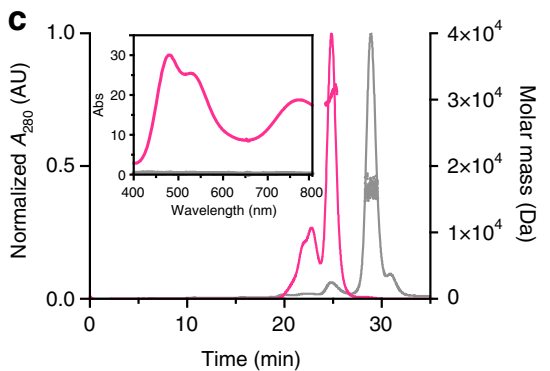

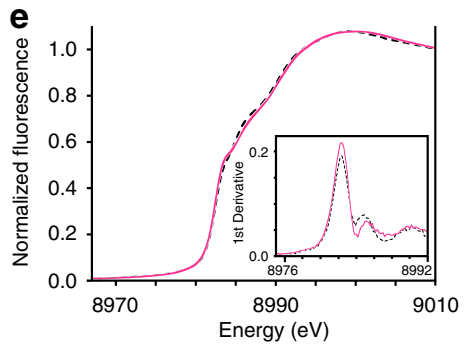

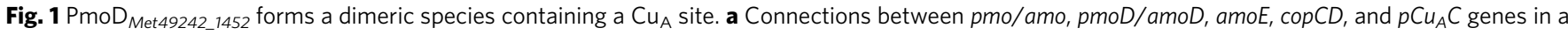
range of $A O B$ and $M O B$ species. b Optical spectra of wild-type PmoD Met49242_1452 periplasmic domain (WT) and variants thereof (200 $\mu$ M protein). All samples were loaded with 2 equivalents copper and desalted prior to data collection. c SEC-MALS profiles for the two species isolated by size exclusion chromatography. Inset shows optical spectra collected at the apex of the predominant peak. Pink traces indicate the CuA species (molar mass 30,540 Da \pm $2 \%$ ) and gray traces indicate the monomeric species (molar mass $16,250 \mathrm{Da} \pm 3 \%$ ). $\mathbf{d} \mathrm{CW}_{\mathrm{X}}$-band EPR spectra of Cu $\mathrm{A}$ PmoD $\mathrm{Met}_{49242} 1452 ; g_{\mathrm{x}}=2.01, g_{\mathrm{y}}=$ $2.05, g_{z}=2.13$. Brackets define the Cu hyperfine splitting at $g_{z}\left(A_{z}\right)$. Conditions: $9.364 \mathrm{GHz}$ microwave frequency, $16 \mathrm{G}$ modulation amplitude, 160 ms time

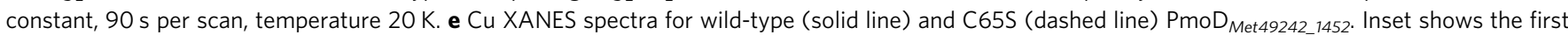
derivatives of both XANES spectra identifying features at 8983.2 and $8987.8 \mathrm{eV}$ (first inflection energies at 8982.5 and $8985.3 \mathrm{eV}$ ) typical for mixed valent $\mathrm{Cu}(+1.5)-\mathrm{Cu}(+1.5)$ species

disulfide bond (Fig. 2a and Supplementary Figure 3b, c). Given that the crystals were obtained from the monomeric PmoDMet49242_1452 species, it is likely that the observed copper-binding site is a crystallization artifact. Nevertheless, comparison of the overall structure to other $\mathrm{Cu}_{\mathrm{A}}$-containing domains shows that the

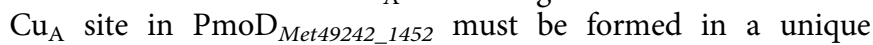
fashion.

The coordinates of $\mathrm{PmoD}_{\text {Met49242_1452 }}$ can be superposed on those of the $\mathrm{Cu}_{\mathrm{A}}$ domains of $\mathrm{CcO}^{21}$ (2CUA (https://doi.org/ $10.2210 / \mathrm{pdb} 2 \mathrm{cua} / \mathrm{pdb}$ ) ) and $\mathrm{N}_{2} \mathrm{OR}^{22}$ (1FWX (https://doi.org/ $10.2210 / \mathrm{pdb} 1 \mathrm{fwx} / \mathrm{pdb})$ ), as well as the engineered azurin $\mathrm{Cu}_{\mathrm{A}}$ domain $^{23}$ (1CC3 (https://doi.org/10.2210/pdb1cc3/pdb)) with root-mean-square deviation (r.m.s.d.) values of 3.06, 2.82, and $2.95 \AA$ for 82,80 , and $82 \mathrm{Ca}$ atoms, respectively (Supplementary Figure $3 \mathrm{~d}, \mathrm{e})$. The $\mathrm{PmoD}_{\text {Met49242_1452 }}$ structure differs from these canonical $\mathrm{Cu}_{\mathrm{A}}$ domain structures in three distinct regions (Fig. $2 \mathrm{~b}$ and Supplementary Figure $3 \mathrm{~b}, \mathrm{c}$ ). First, the $\mathrm{N}$-terminal histidine ligand in the $\mathrm{Hx}_{34} \mathrm{Cx}_{3} \mathrm{Cx}_{3} \mathrm{Hx}_{2} \mathrm{M} \mathrm{C \textrm {Cu } _ { \mathrm { A } }}$ motif typically derives from the loop between $\beta 3$ and $\beta 4$, but $\operatorname{PmoD}_{\text {Met49242 } 1452}$ contains a small helix in place of this loop and lacks a histidine in the equivalent position. Second, the loop between $\beta 7$ and $\beta 8$ provides the other four $\mathrm{Cu}_{\mathrm{A}}$ ligands, but $\mathrm{PmoD}_{\text {Met49242_1452 lacks not only }}$ this sequence motif, but also any histidine, cysteine, or methionine residues in this area. Instead, this region in $\mathrm{PmoD}_{\text {Met49242_1452 }}$ is an extended $\beta$ hairpin (Fig. 2b). Finally, the N-terminal region of $\mathrm{PmoD}_{\text {Met49242 } 1452}$ diverges in the orientation of $\beta 1$ and $\beta 2$, as well as the presence of an additional $\beta$ strand prior to $\beta 1$. These changes at the $\mathrm{N}$ terminus are likely due to the intramolecular disulfide bond (Supplementary Figure $3 \mathrm{~b}$ ).

Instead of the canonical $\mathrm{Cu}_{\mathrm{A}}$ ligands, $\mathrm{PmoD}_{\text {Met49242_1452 }}$ contains a cluster of surface-exposed cysteine, methionine, and histidine residues near its $\mathrm{N}$ terminus, including the universally conserved cysteine residues Cys41 and Cys65 (Fig. 2c). A variant

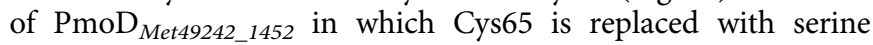

retains the $\mathrm{Cu}_{\mathrm{A}}$ features (Fig. 1b,e, Supplementary Figure 2e-h), and exhibits nearly complete dimerization upon addition of copper (Supplementary Figure 1c) with $0.80 \pm 0.02$ equivalents of $\mathrm{Cu}$ bound per protein molecule. While these data indicate that Cys65 is not a $\mathrm{Cu}_{\mathrm{A}}$ ligand, the reduced copper stoichiometry compared to wild type indicates that Cys65 may bind an additional copper ion. By contrast, replacement of Cys41 with serine abolished appearance of the $\mathrm{Cu}_{\mathrm{A}}$ spectral features. Since $\mathrm{PmoD}_{\text {Met49242_1452 }}$ only contains these two conserved cysteine residues and $\mathrm{Cu}_{\mathrm{A}}$ sites require two bridging thiolates, the $\mathrm{Cu}_{\mathrm{A}}$ site

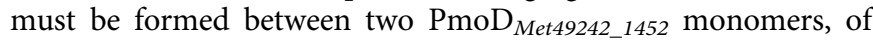
which each contributes a Cys41 ligand. The periplasmic domain of $\mathrm{PmoD}_{\text {Met49242_1452 }}$ contains four histidine residues, of which one, His51, is located near Cys41 (Fig. 2c). Replacement of His51 with alanine also eliminates $\mathrm{Cu}_{\mathrm{A}}$ formation, as does replacement of Met49 with alanine (Fig. 1b), implicating these two residues as ligands. Thus, despite the overall similarity in fold to other $\mathrm{Cu}_{\mathrm{A}}$ domains, the $\mathrm{PmoD} \mathrm{Cu}_{\mathrm{A}}$ site is formed by two protein molecules and a completely different part of the protein structure (Fig. 2d) in contrast to all previously characterized $\mathrm{Cu}_{\mathrm{A}}$ centers which are housed within a single cupredoxin domain.

Disruption of $p m o D$ in vivo results in a copper-dependent growth defect. To assess the role of PmoD in vivo, we disrupted the $p m o D$ gene in the extended copy of the pmo operon (containing $p m o C A B$ as well as the $p m o D, \operatorname{cop} C, \operatorname{cop} D$, and $p C u_{A} C$

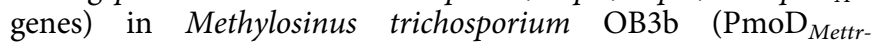
DRAFT_0381). Unlike Methylocystis sp. Rockwell, Methylosinus trichosporium OB3b also possesses genes for the soluble, ironcontaining MMO (sMMO) and for proteins related to the biosynthesis, regulation, and transport of the siderophore-like copper chelator methanobactin $(\mathrm{Mbn})^{24}$. Under copper starvation conditions, sMMO and Mbn are produced; both processes 


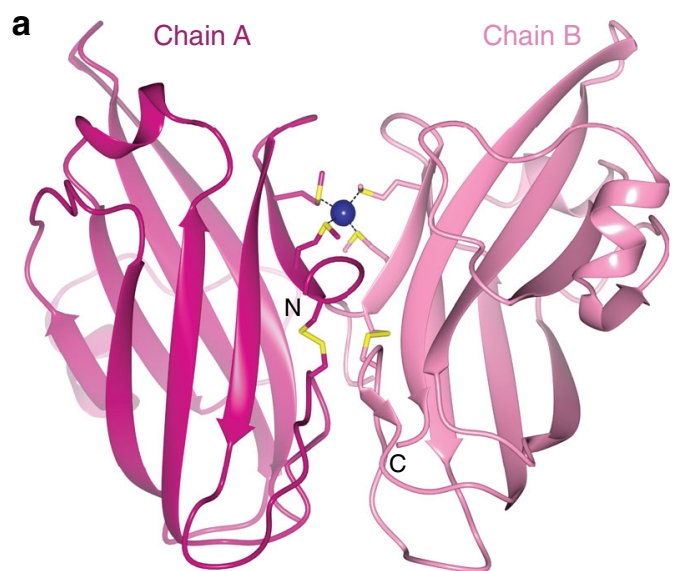

C

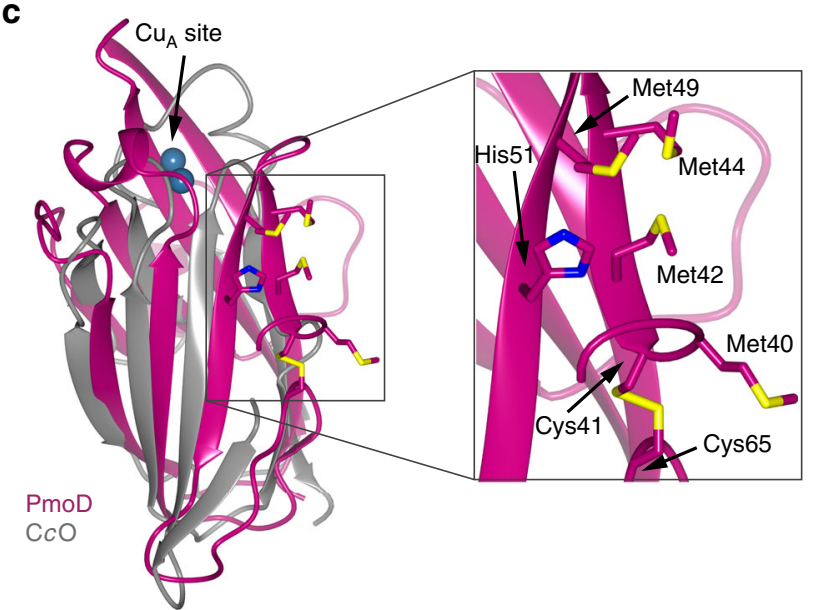

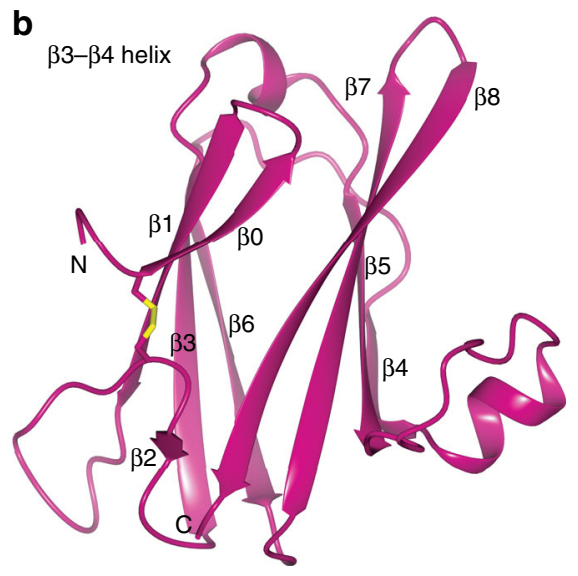

d

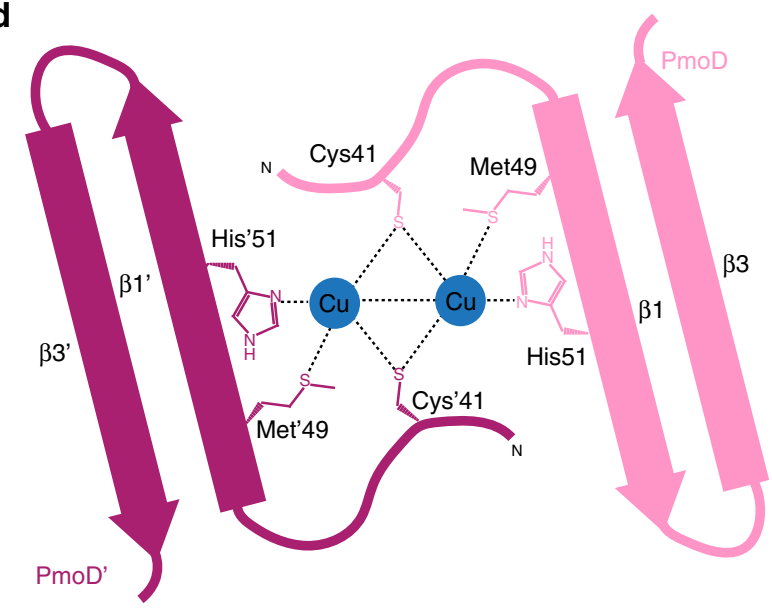

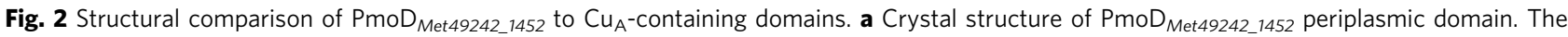
asymmetric unit of the crystal is shown as a ribbon diagram, with chain A in magenta and chain B in pink. The copper ion is depicted as a blue sphere and

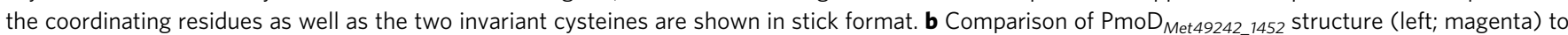
the $\mathrm{Cu}_{\mathrm{A}}$-containing domain of $T$. thermophilus $\mathrm{CCO}$ (PDB: 2CUA). Secondary structure elements are labeled, and the $\mathrm{Cu}_{\mathrm{A}}$ site in $\mathrm{CcO}$ is indicated with $\mathrm{Cu}$ ions shown as spheres and coordinating ligands in stick format. c Superposition of $\mathrm{PmoD}_{\text {Met49242_1452 }}$ periplasmic domain (magenta) with $\mathrm{CcO}$ (gray) colored as in (b). The box indicates the region containing the PmoD $\mathrm{Met}_{49242} 1452$ candidate metal binding ligands, and the inset shows a close-up of the

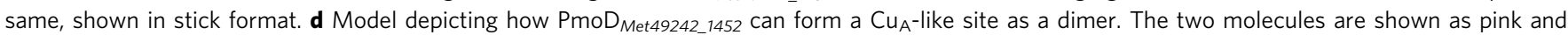
magenta cartoons, with the residues identified as ligands indicated

are associated with characteristic phenotypes. When copper is bioavailable, these genes are repressed as part of the so-called copper switch, and the pMMO genes are mildly up-regulated ${ }^{10}$. Growth of both the wild-type and $\triangle p m o D$ strains was monitored in either copper-free media or media supplemented with $10 \mu \mathrm{M}$ $\mathrm{CuSO}_{4}$. Under copper starvation conditions, $\triangle p m o D$ Methylosinus trichosporium OB3b is phenotypically similar to the wild-type strain. The strains grow at a comparable rate (Fig. 3a), and both produce Mbn (Supplementary Figure 4c, d), exhibit sMMO activity (Supplementary Figure 4e), and produce sMMO (Supplementary Figure $4 \mathrm{f}$ ). Under copper-replete conditions, however, $\triangle p m o D$ Methylosinus trichosporium OB3b exhibits a pronounced growth defect. Cultures grown in copper-supplemented media produce significantly less cell density after 1 week of growth (Fig. 3b), and the $\triangle p m o D$ strain also exhibits a growth defect on nitrate mineral salts (NMS) agar plates supplemented with $\mathrm{CuSO}_{4}$ (Supplementary Figure 4a, b). This phenotype is distinct from the wild-type strain which exhibits a slight increase in growth rate under copper-replete conditions ${ }^{25}$ (Fig. 3b). Despite the growth defect in the presence of copper, the $\triangle p m o D$ strain, like the wildtype strain, does not produce Mbn (Supplementary Figure $4 \mathrm{~g}, \mathrm{~h}$ ), and no longer exhibits sMMO activity (Supplementary Figure 4i). While the sMMO subunits are significantly less abundant in copper-replete cell lysates, the pMMO subunits are detected in both the wild-type and $\triangle p m o D$ Methylosinus trichosporium OB3b strains (Supplementary Figure 4j). Thus, PmoD MettrDRAFT_0381 $_{1}$ does not appear to play a role under sMMO-utilizing conditions, but is important for growth under pMMO-utilizing conditions. It is not clear, however, whether the $\mathrm{Cu}_{\mathrm{A}}$ site is linked to the observed growth defect.

PmoD homologs exhibit varying levels of copper-dependent regulation. Interestingly, this copper-dependent growth defect is observed despite the presence of seven additional PmoD homologs encoded in the Methylosinus trichosporium OB3b genome, suggesting that all PmoD proteins are not functionally equivalent. We previously showed that the components of the full Methylosinus trichosporium OB3b pmo operon (pmoCAB, pmoD, copC, $\operatorname{cop} D$, and $\left.p C u_{A} C\right)$ are very mildly up-regulated by $\operatorname{copper}^{10}$, and other studies have shown that in $\mathrm{AOB}$, amoD (and, if present, $a m o E$ ) are co-up-regulated and co-transcribed with $a m o C A B$ upon exposure to ammonia ${ }^{12,26}$. The regulation of $p m o D$ homologs beyond the pmo operon has not been investigated. Therefore, we conducted time-dependent, copper-responsive quantitative polymerase chain reaction (qPCR) analysis of all 
a

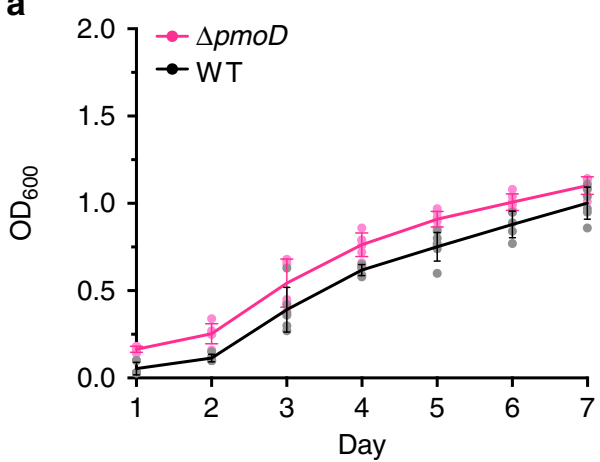

b

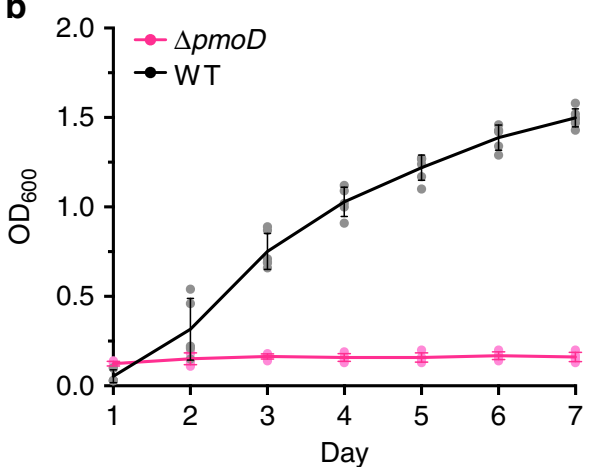

C

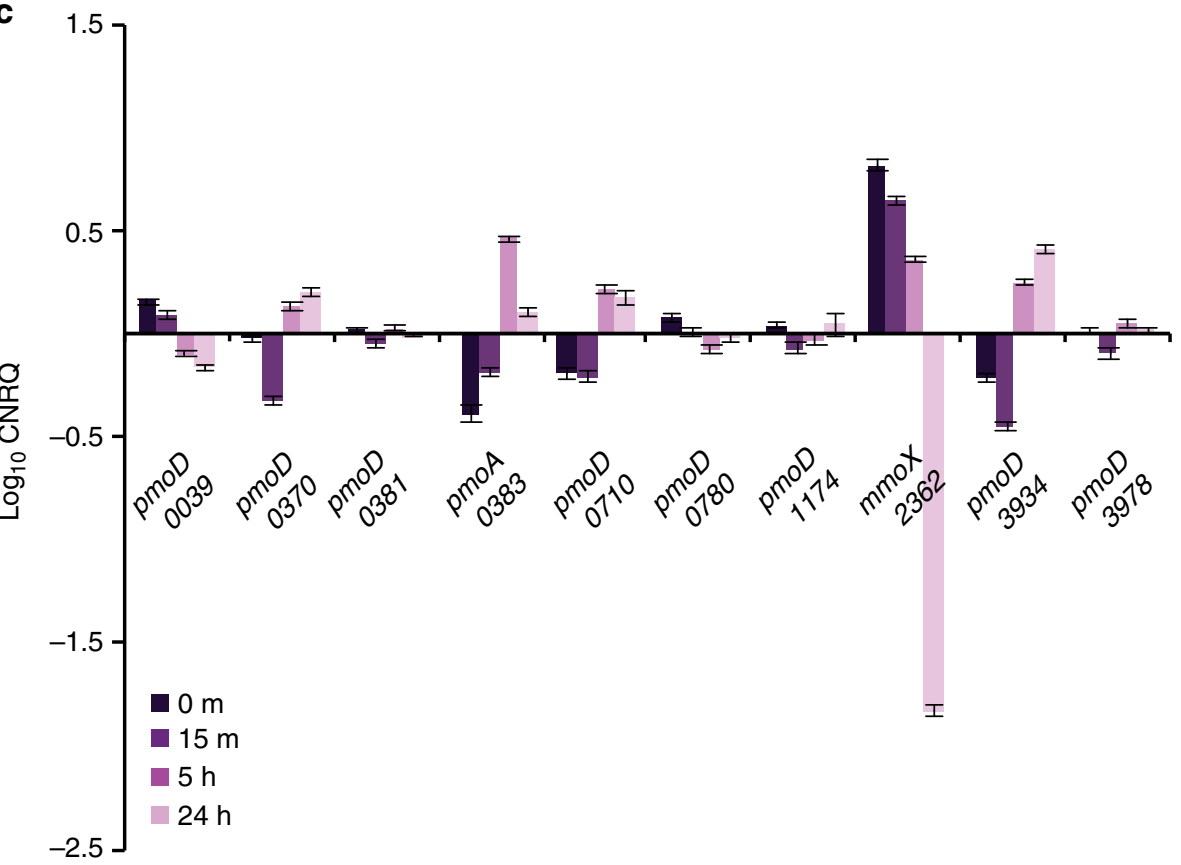

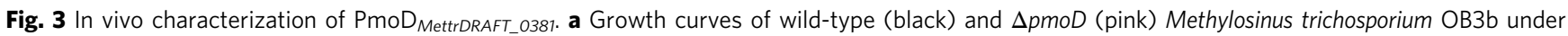
copper starved conditions. Error bars represent s.d., $n=5-6$. b Growth curves of wild-type (black) and $\Delta$ pmoD (pink) Methylosinus trichosporium OB3b grown in the presence of $10 \mu \mathrm{M} \mathrm{CuSO}_{4}$. Error bars represent s.d., $n=5-6$. c qPCR analysis of pmoD genes in Methylosinus trichosporium OB3b at four timepoints ( 0 min at $0 \mu \mathrm{M} \mathrm{CuSO}_{4}, 15 \mathrm{~min}$ at $12.5 \mu \mathrm{M} \mathrm{CuSO}_{4}, 5 \mathrm{~h}$ at $12.5 \mu \mathrm{M} \mathrm{CuSO}_{4}, 24 \mathrm{~h}$ at $12.5 \mu \mathrm{M} \mathrm{CuSO}_{4}$ ). Regulatory changes are shown as log $0^{-}$ transformed normalized relative quantities (NRQs). The four-digit code beneath the gene name represents the locus tag (in MettrDRAFT_NNNN format). Two non-pmoD genes are included for comparison: components of the two MMOs, pMMO (pmoA_0383) and sMMO (mmoX_2362), which are reciprocally regulated by copper. The clearest copper-responsive regulation is observed for the copC-adjacent pmoD MettrDRAFT_0039 (the genes are both copper down-regulated, and regulatory changes are correlated with those observed for components of the mmo and $m b n$ operons) and for the $p C u_{A} C$-adjacent pmoD MettrDRAFT_3934 (the genes are both copper up-regulated, and regulatory changes are correlated with those observed for components of the pmo operon and csp1). Error bars represent standard error between three biological replicates, each containing three technical replicates. Data points are shown in Supplementary Figure 5

Methylosinus trichosporium OB3b non-operon pmoD genes. We observe varying patterns of copper-dependent regulation, with some $p m o D$ genes mildly repressed, some up-regulated, and several not regulated by copper at all (Fig. $3 \mathrm{c}$ and Supplementary Figure 5), further supporting that not all $\mathrm{PmoD}$ proteins are functionally equivalent. A recent RNA-sequencing study on Methylosinus trichosporium OB3b that lacks the time-resolved component of these experiments is nevertheless consistent with the observed regulatory patterns for $p m o D s$ with significant regulatory changes and/or correlated co-regulation with other copper-responsive genes ${ }^{27}$. Moreover, differential regulation of pmoD genes in response to copper is also observed for Methylococcus capsulatus (Bath) ${ }^{28}$ which has two pmoD genes of which neither is located in its pmo operon. These regulatory patterns combined with the $\triangle p m o D$ Methylosinus trichosporium OB3b phenotype suggest that PmoD homologs play distinct roles in vivo.

In support of nonredundant functionality, the production of many PmoD homologs is evident by proteomics at variable levels. We detected PmoD soluble domains and predicted C-terminal helices, but not the N-terminal signal peptides, in membrane fractions or whole cell lysate from five different methanotrophs (Supplementary Figure 6). For Methylocystis sp. Rockwell, 5 of the 11 PmoD homologs are observed in solubilized membrane fractions, including $\mathrm{PmoD}_{\text {Met49242_1452 }}$ (Supplementary Figure 6a). In solubilized membrane fractions from Methylomicrobium buryatense 5GB1C (Supplementary Figure 6b) and Methylomicrobium alcaliphilum 20Z (Supplementary Figure 6c), whose genomes each contain two PmoD homologs, both homologs are detected. In the case of Methylococcus capsulatus (Bath) 
(Supplementary Figure 6d), which also has two PmoD homologs, one was observed. In whole cell lysate from Methylosinus trichosporium OB3b grown under copper-replete conditions, six of eight PmoD homologs are observed, including those encoded by genes adjacent to $c o p C D, p C u_{A} C$, and $p m o C A B$ (Supplementary Figure 6e).

Bioinformatics analyses suggest functional differences. To address potential functional differences among PmoD homologs, we performed a detailed bioinformatic analysis of all PmoD sequences identifiable in the Joint Genome Institute/Integrated Microbial Genomes (JGI/IMG) genome database. The vast majority of these are found in $\mathrm{MOB}$ and $\mathrm{AOB}$, and all are found in species with genomes containing at least one operon encoding a copper membrane monooxygenase (CuMMO) related to pMMO/AMO (Fig. 4a). Notably, the only genomes that encode pMMO/AMO homologs, but not PmoD proteins, are species that oxidize neither methane nor ammonia such as strains of $\mathrm{Myco-}$ bacteria and Nocardiodes ${ }^{29}$ (Fig. 4b). The number of PmoD homologs per genome ranges from one (e.g., Methylovulum and Methylogaea species, and some species outside of canonically methanotrophic genera) to 11 (Methylocystis sp. Rockwell), all of which differ in sequence and genomic context. Most canonical $\mathrm{MOB}$ and $\mathrm{AOB}$ genomes contain at least two PmoD homologs. An alignment of all putative PmoD amino acid sequences was used to construct a preliminary PmoD profile hidden Markov model (HMM) and to identify several core sequence motifs involving the two invariant cysteines and other putative metal binding residues (Supplementary Figure 7). Genomic neighborhood analysis provides additional insight into the link between the various $\mathrm{PmoD}$ proteins and $\mathrm{pMMO} / \mathrm{AMO}$ (Supplementary Figure 8). $\mathrm{PmoD}$ proteins containing either a $\mathrm{Cx}_{7} \mathrm{MxHx}_{n} \mathrm{C}$ motif (like $\mathrm{PmoD}_{\text {Met49242_1452) }}$ ) or a $\mathrm{Cx}_{8} \mathrm{MHx}_{\mathrm{n}} \mathrm{C}$ motif comprise $23.6 \%$ and $13.4 \%$, respectively, of all PmoDs (Fig. 4c, Supplementary Figure 7). These subsets are predominantly associated with $\mathrm{pmol}$ amo operons (the latter annotated in $\mathrm{AOB}$ as $a m o D$ and the former as amoE) and are also found in the proximity of some lone $p m o C$ genes (Fig. $4 \mathrm{~d}$ ). In $\alpha-\mathrm{MOB}$, the $p m o D$ genes found in pmo operons encode PmoDs with the $\mathrm{Cx}_{7} \mathrm{MxHx}_{\mathrm{n}} \mathrm{C}$ motif, as observed in the proteins encoded by $a m o E$ and not in $a m o D$. The close association between genes encoding PmoD and pMMO/ $\mathrm{AMO}$ is markedly different from the neighboring genes encoding CopCs, CopDs, and $\mathrm{PCu}_{\mathrm{A}} \mathrm{Cs}$ which are quite common in other prokaryotes $^{30}$. These in-operon PmoDs are likely to have functions specific to $\mathrm{PMMO}$ and $\mathrm{AMO}$, consistent with the phenotype observed in the $\triangle p m o D$ Methylosinus trichosporium OB3b strain (Fig. 3a).

$\mathrm{Cu}_{\mathrm{A}}$ site formation is limited to homologs with a $\mathrm{Cx}_{7} \mathrm{MxHx}_{\mathrm{n}} \mathrm{C}$ motif. Since the ligand set identified for the $\mathrm{Cu}_{\mathrm{A}}$ site in $\mathrm{PmoD}_{\text {Met49242_1452 }}$ (Cys41, Met49, and His51), along with Cys65, which is not involved in the $\mathrm{Cu}_{\mathrm{A}}$ site, corresponds to the $\mathrm{Cx}_{7} \mathrm{MxHx}_{\mathrm{n}} \mathrm{C}$ motif (Fig. 4c, Supplementary Figure 7), we investigated whether other PmoD homologs containing this motif are also capable of forming a $\mathrm{Cu}_{\mathrm{A}}$ center. We expressed and purified PmoD ${ }_{\text {O5ODRAFT_02836, a homolog from Methylocystis parvus }}$ OBBP. According to metal quantitation and EPR and optical spectroscopic characterization, $\mathrm{PmoD}_{\text {O5ODRAFT_02836, like }}$ $\mathrm{PmoD}_{\text {Met49242_1452, }}$ binds copper (Supplementary Table 3) and forms a $\mathrm{Cu}_{\mathrm{A}}$ species (Fig. 4e, Supplementary Table 4 , Supplementary Figure 9), although a significant fraction (estimated at $\sim 50 \%$ ) of the $\mathrm{PmoD}_{\text {Met49242_1452 }}$ EPR signal is attributable to mononuclear type $2 \mathrm{Cu}(\mathrm{II})$ resonance $\mathrm{B}^{31,32}$.

We also examined the genomic neighborhoods of genes encoding PmoDs with other putative metal binding motifs and conducted in vitro metal binding and spectroscopic experiments on representative members of these classes. The representative $\mathrm{Cx}_{8} \mathrm{Mx}_{\mathrm{n}} \mathrm{C}$ motif-containing $(7.9 \%$ of all PmoD homologs, commonly near genes encoding multicopper oxidases, $\mathrm{PCu}_{\mathrm{A}} \mathrm{Cs}$, and $\mathrm{ABC}$ transporters) and $\mathrm{Cx}_{9} \mathrm{Hx}_{\mathrm{n}} \mathrm{C}$ motif-containing (22.2\%, genes often found near copC) PmoDs Methylocystis parvus OBBP $\mathrm{PmoD}_{\text {O5ODRAFT_02342 and Methylosinus trichosporium }}$ OB3b PmoD MetrDRAFT_0370 bind copper (Supplementary Table 3), but do not exhibit optical or EPR spectroscopic features consistent with a $\mathrm{Cu}_{\mathrm{A}}$ site (Fig. 4e, Supplementary Figure 9). In addition, a large number of PmoDs have no conserved metal binding residues beyond the $\mathrm{Cx}_{\mathrm{n}} \mathrm{C}$ motif $(29.0 \%)$ and typically neighbor genes of unknown relevance or are adjacent to $\operatorname{cop} C$ genes (Supplementary Figure 8). While one such $\mathrm{PmoD}$, $\mathrm{PmoD}_{\text {Met49242_0515, }}$, also binds copper, it too cannot form a $\mathrm{Cu}_{\mathrm{A}}$ species (Supplementary Table 3, Fig. 4e, Supplementary Figure 9). Thus, $\mathrm{Cu}_{\mathrm{A}}$ site formation is confined to $\mathrm{Cx}_{7} \mathrm{MxHx}_{\mathrm{n}} \mathrm{C}$-containing PmoDs encoded by genes within extended pmo/amo operons.

\section{Discussion}

PmoD/AmoD represent a family of copper-binding proteins specific to $\mathrm{MOB}$ and $\mathrm{AOB}$, the key players in global carbon and nitrogen cycling. The subset of PmoD homologs encoded in genomic proximity to and co-regulated with $\mathrm{PMMO} / \mathrm{AMO}$ contains an unprecedented type of $\mathrm{Cu}_{\mathrm{A}}$ site and is important for copper-dependent growth on methane. PmoD homologs are more closely correlated with CuMMOs than any other recently proposed members of the $\mathrm{MOB} / \mathrm{AOB}$ copper homeostasis system, including the periplasmic copper sponge protein Csp1/2, the cytoplasmic copper sponge protein Csp3, the secreted copperbinding proteins CorA/MopE, and the copper-binding chalkophore Mbn (Fig. 4a). This observation strongly supports a unique role for PmoDs in the function of CuMMOs.

Potential functions of $\mathrm{PmoD}$ include providing reducing equivalents to drive $\mathrm{pMMO}$ reactivity, facilitating copper loading of pMMO, or even structurally stabilizing pMMO within the membrane. The specific biological role of $\mathrm{PmoD}$, including whether its function in vivo is mediated via the homodimeric $\mathrm{Cu}_{\mathrm{A}}$ species, remains to be determined. More comprehensive characterization of the unusual $\mathrm{Cu}_{\mathrm{A}}$ site, combined with additional in vivo and in vitro studies of PmoD including its transmembrane helix, are needed to address these possibilities. Furthermore, functional differences among the entire $\mathrm{PmoD} / \mathrm{AmoD}$ family remain to be elucidated. Given the prevalent genomic proximity of $p m o D / a m o D$ genes to those encoding a range of coppercontaining proteins, it is likely that additional copper centers and copper-related functions will be uncovered.

\section{Methods}

Cloning and construct design for PmoD expression plasmids. The expression constructs for the $\mathrm{N}$-terminally $\mathrm{His}_{6}$-tagged tobacco etch virus (TEV)-cleavable PmoD periplasmic domains were all prepared in the pSCG-His vector by Anthony Gizzi and Steven Almo (Albert Einstein College of Medicine) using the primers listed in Supplementary Table 5. The cysteine variants in $\mathrm{PmoD}_{\text {Met49242_1452 were }}$ generated via a QuikChange Lightning kit as directed (Agilent), using primers listed in Supplementary Table 5. The Met49Ala and His51Ala variants were synthesized by Genscript along with a TEV cleavage site before the $\mathrm{N}$-terminal residue and subcloned into the pET28a vector. All constructs include an additional vectorderived serine and methionine at the $\mathrm{N}$ terminus.

Expression and purification of the PmoD periplasmic domains. All PmoD periplasmic domain constructs were expressed and purified following the same protocol. Plasmid DNA was transformed into $\mathrm{BL} 21^{\star}(\mathrm{DE} 3)$ cells (Novagen). Overnight cultures in $\mathrm{LB}$ media were grown at $37^{\circ} \mathrm{C}$ with agitation at $200 \mathrm{rpm}$, followed by inoculation into $1 \mathrm{~L}$ autoinduction media ${ }^{33}$ and incubation at $37^{\circ} \mathrm{C}$ with agitation at $200 \mathrm{rpm}$ until reaching an optical density at $600 \mathrm{~nm}$ of 0.6 . The temperature was then reduced to $22^{\circ} \mathrm{C}$, and the cells were harvested after $\sim 18 \mathrm{~h}$ by centrifugation at $6000 \times g$ for $15 \mathrm{~min}$. The resulting cell pellet was resuspended in lysis buffer ( $20 \mathrm{mM}$ imidazole, $20 \mathrm{mM}$ Tris, $\mathrm{pH} 8.0,500 \mathrm{mM} \mathrm{NaCl})$ supplemented 


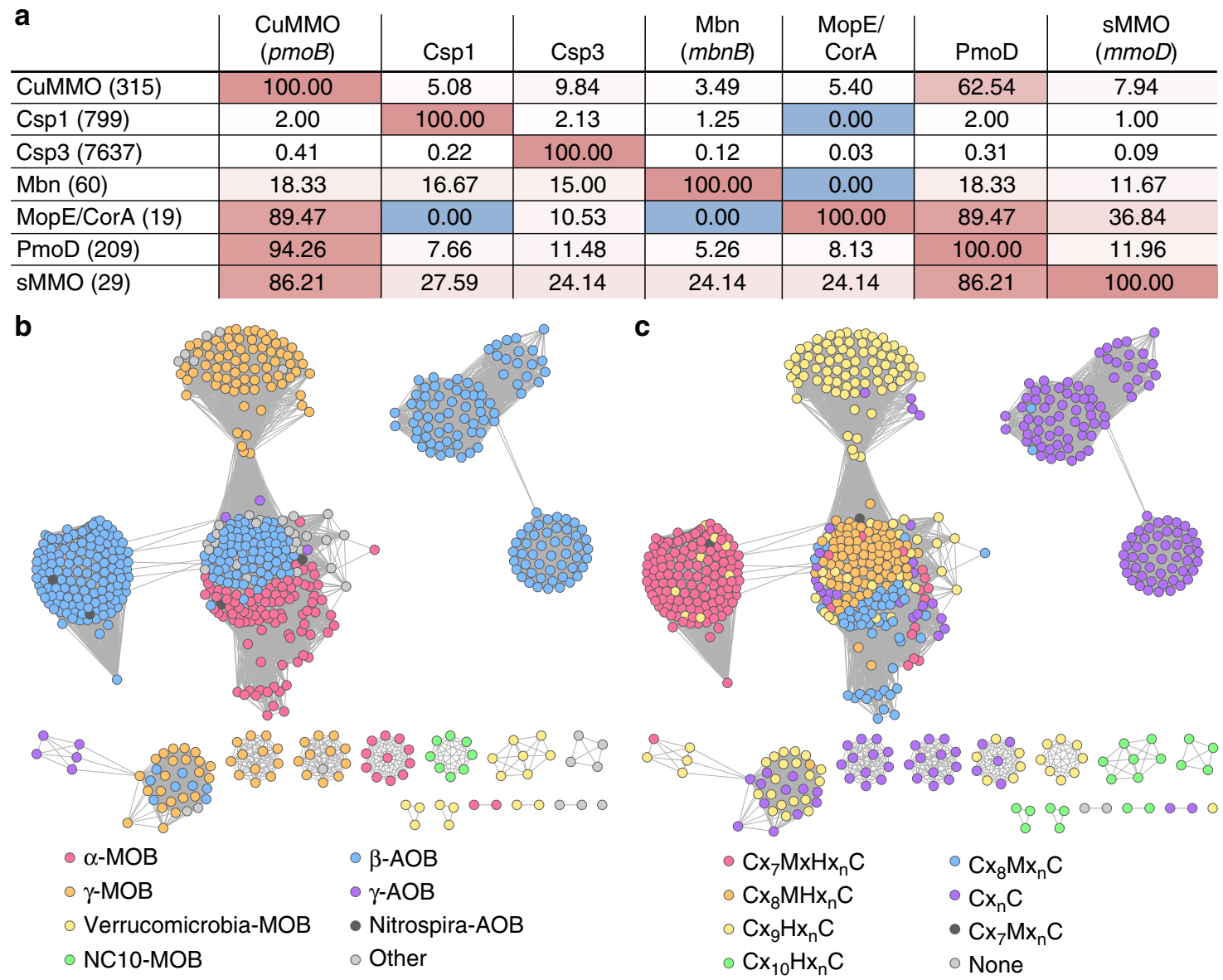

d

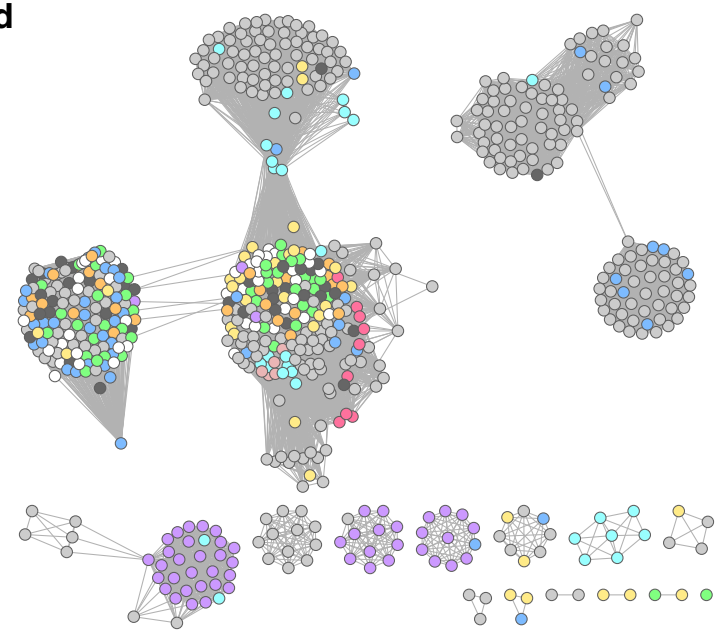

- pmoCABED copCD

- $\mathrm{copC} \quad \mathrm{pmoC}$

- mco - Other

- $p \mathrm{Cu}_{A} \mathrm{C} \quad$ None e

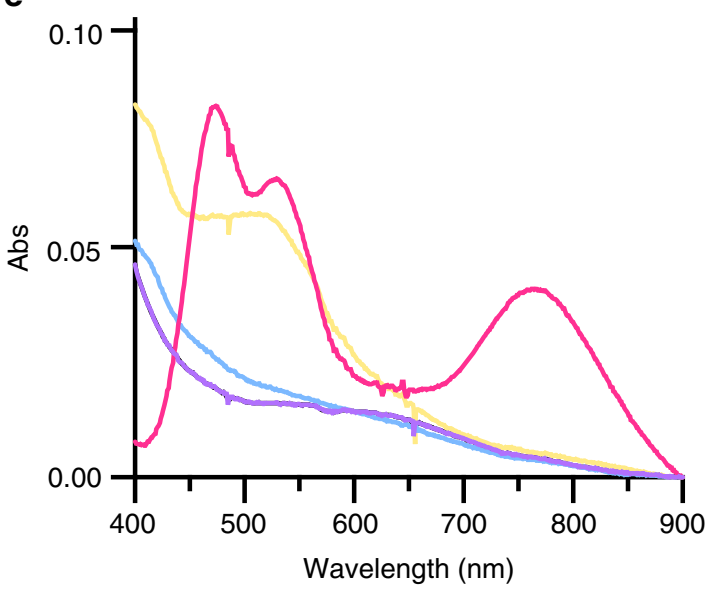

$$
\begin{aligned}
& -\mathrm{PmoD}_{\text {O5ODRAFT_02836 }}\left(\mathrm{Cx}_{7} \mathrm{MxHx}_{\mathrm{n}} \mathrm{C}\right) \\
& -\mathrm{PmoD}_{\text {O5ODRAFT_02342 }}\left(\mathrm{Cx}_{8} \mathrm{Mx} \mathrm{x}_{\mathrm{n}} \mathrm{C}\right) \\
& -\mathrm{PmoD}_{\text {MettrDRAFT_0370 }}\left(\mathrm{Cx}_{9} \mathrm{Hx} \mathrm{x}_{\mathrm{n}} \mathrm{C}\right) \\
& -\mathrm{PmoD}_{\text {Met49242_0515 }}\left(\mathrm{Cx}_{\mathrm{n}} \mathrm{C}\right)
\end{aligned}
$$

Fig. 4 PmoD subfamilies and their connections to copper homeostasis. a Genomes present in the JGI/IMG database were analyzed for the presence of genes with a proposed relationship to the methanotroph copper homeostasis, including csp1/2 (TIGR04401), copper membrane monooxygenases (CuMMOs) via a/pmoB (PF04744/TIGR03079), Mbn via mbnB (TIGR04159), pmoD (the dataset in this paper), csp3/DUF326 (PF03860), mopE/corA (via BLAST, no profile HMM available), and sMMO via mmoD (TIGR04550, absent in non-sMMO soluble diiron monooxygenase enzymes). The strongest reciprocal relationship is observed between PmoDs and pMMO components. b A sequence similarity network (SSN) for PmoD homologs was constructed using the EFI/EST network generation tool and an E-value cutoff of 21, colored by AOB/MOB distribution among PmoD homologs. c SSN colored by core

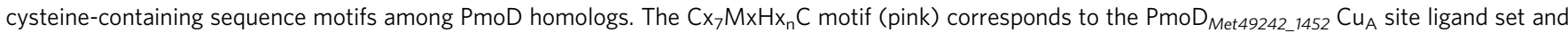
is also present in AmoEs. d SSN colored by proximity to copper-related genes, including amoCAB/pmoCAB operons (pmo operons), lone amoC/pmoC genes $(p m o C)$, copCD pairs or lone copC genes, $p C u_{A} C$ genes, genes encoding multicopper oxidases, and genes encoding additional pmoD homologs. e Optical spectra of representative classes of copper-loaded PmoD homologs denoted by locus tag and metal binding motif 
with $1 \mathrm{mM}$ DTT, $1 \mathrm{mg} \mathrm{mL}^{-1}$ DNase I (Sigma), and $1 \mathrm{mM}$ phenylmethylsulfonyl fluoride dissolved in ethanol (EtOH). Cells were lysed via sonication for $15 \mathrm{~min}$ with $1 \mathrm{~s}$ pulses. Cell debris was removed by centrifugation at $24,000 \times g$ for $1 \mathrm{~h}$.

The resulting supernatant was then applied to NiNTA resin (Qiagen) preequilibrated with chilled lysis buffer. The flow-through was discarded, and the resin was washed with 5 column volumes of lysis buffer. $\mathrm{His}_{6}-\mathrm{TEV}-\mathrm{PmoD}$ was eluted with 2 column volumes of elution buffer consisting of lysis buffer with $500 \mathrm{mM}$ imidazole. To remove the $\mathrm{His}_{6}$ tag, TEV protease was added to the eluate, and the sample was dialyzed in $10 \mathrm{kDa}$ molecular weight cutoff (MWCO) SnakeSkin dialysis tubing (Thermo) against $20 \mathrm{mM}$ Tris, $\mathrm{pH}$ 7.0, and $1 \mathrm{mM}$ DTT overnight at $4{ }^{\circ} \mathrm{C}$. Following cleavage, the dialyzed sample was then re-applied to NiNTA resin to remove the TEV protease and the cleaved tag. The flow-through containing purified PmoD was then concentrated in $10 \mathrm{kDa}$ MWCO Amicon spin concentrators (Millipore) and either used immediately or flash frozen in liquid nitrogen and stored at $-80^{\circ} \mathrm{C}$.

Metallation of PmoD. Purified PmoD samples were buffer exchanged by dilution into reductant-free buffer (20 mM Tris, $\mathrm{pH} 7.0)$ and concentrating in $10 \mathrm{kDa}$ MWCO spin concentrators (Millipore) to $200-600 \mu \mathrm{M}$ followed by the slow addition of 2 molar equivalents of $\mathrm{CuSO}_{4}$ with constant mixing on ice. Excess copper was then removed either using a disposable PD-10 desalting column (GE Healthcare Life Sciences) or by size exclusion chromatography using a HiLoad 16/ 600 Superdex 75 column (GE Healthcare Life Sciences). By the latter method, two distinct $\mathrm{PmoD}_{\text {Met } 49242 \_1452}$ species can be resolved, the dimeric species that forms the $\mathrm{Cu}_{\mathrm{A}}$-like site and a monomeric copper-bound species. All protein concentrations were measured using the Bradford assay with a standard curve generated from known concentrations of bovine serum albumin. Optical spectra were collected using copper-loaded samples containing $200 \mu \mathrm{M}$ protein in a quartz cuvette (Helma) at room temperature using an Agilent 8453 spectrophotometer. For metal analysis, all samples were first desalted on a PD-10 column into metal-free buffer (20 mM Tris, pH 7.5) and digested in 5\% nitric acid in metal-free tubes (VWR). Standard curves were generated using a dilution series of a custom multi-element standard (Inorganic Ventures). The copper content of the samples was determined using a Thermo iCAP 7600 ICP-OES instrument in the Quantitative Bio-element Imaging Center (QBIC) core facility at Northwestern University.

Size exclusion chromatography with multi-angle light scattering. SEC-MALS was used to determine the molar masses of the two PmoD species resolved by SEC. Each peak was pooled and concentrated to $2-4 \mathrm{mg} \mathrm{mL}^{-1}$ in $10 \mathrm{kDa}$ MWCO concentrators (Millipore). Samples were analyzed using an Agilent 1260 series high-performance liquid chromatography (HPLC) system equipped with diodearray detection absorbance in-line with a DAWN HELEOS II multi-angle static light scattering detector (Wyatt Technology), a QELS dynamic light scattering detector (Wyatt Technology), and a T-rEx differential refractive index detector (Wyatt Technology). Then, $300 \mu \mathrm{L}$ protein was applied to a Superdex 75 Increase $10 / 300 \mathrm{GL}$ column (GE Healthcare) that had been pre-equilibrated in a mobile phase consisting of $20 \mathrm{mM}$ Tris, $\mathrm{pH}$ 7.0. The mobile phase and protein sample prior to injection were maintained at $4{ }^{\circ} \mathrm{C}$ and the column was kept at $8^{\circ} \mathrm{C}$. Each sample was run at $0.4 \mathrm{~mL} \mathrm{~min}^{-1}$ for $60 \mathrm{~min}$. Optical spectra were also recorded at the apex of each peak. Data were processed and analyzed using Astra software version 5.3.4 (Wyatt Technology).

Electron paramagnetic resonance spectroscopy. EPR samples were prepared in $20 \mathrm{mM}$ Tris, $\mathrm{pH} 7.0$, at concentrations of $100-300 \mu \mathrm{M}$ protein. Protein solution was loaded into Wilmad quartz X-band EPR tubes (Sigma Aldrich) and samples were then frozen in liquid nitrogen, where they were stored until analysis. Continuous wave (CW) X-band spectra were collected on a Bruker ESP-300 spectrometer with an Oxford Instruments ESR-900 helium flow cryostat.

X-ray absorption spectroscopy. The $\mathrm{Cu}_{\mathrm{A}}$-like dimeric species of wild-type

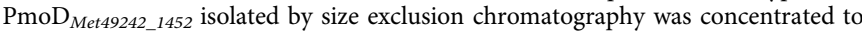
$1.8 \mathrm{mM} \mathrm{Cu}(1.26 \mathrm{mM}$ protein) in $20 \mathrm{mM}$ Tris, $\mathrm{pH} 7.0,30 \%$ glycerol. The C65S sample was concentrated to $900 \mu \mathrm{M} \mathrm{Cu}(740 \mu \mathrm{M}$ protein). Each sample was loaded into a $2 \mathrm{~mm}$ Lucite EXAFS cell wrapped in Kapton tape, flash frozen in liquid nitrogen, and stored in liquid nitrogen until exposure to X-ray radiation. X-ray absorption spectroscopy (XAS) data were collected at the Stanford Synchrotron Radiation Lightsource on beamline 9-3 which is equipped with a Si[220] doublecrystal monochromator with an upstream mirror for focusing and harmonic rejection. Fluorescence spectra were collected using a 100-element Ge solid-state detector (Canberra). During data collection, the continuous-flow liquid helium cryostat (Oxford Instruments) was stabilized at $10 \mathrm{~K}$. Copper excitation data were collected using a $6 \mu \mathrm{m}$ nickel filter and solar slits placed between the cryostat and detector to reduce scattering fluorescence. XAS spectra were measured using $5 \mathrm{eV}$ steps in the pre-edge region $(8750-8960 \mathrm{eV}), 0.25 \mathrm{eV}$ steps in the edge region (8986-9050 eV), and $0.05 \AA^{-1}$ increments in the EXAFS region (to $k=13.3 \AA^{-1}$, integrating from 1 to $25 \mathrm{~s}$ in a $k^{3}$ weighted manner for a total scan length of approximately $40 \mathrm{~min}$ ). A Cu foil spectrum was collected simultaneously with each protein spectrum for energy calibration, with an assigned first inflection point at $8980.3 \mathrm{eV}$. Spectra were closely monitored for any photodamage and slight photoreduction was observed in the second scan at each exposure position. To quantitate the extent and impact of photoreduction, individual spectra were collected at unique positions on the sample surface using a matrix positioning grid (ensuring a new face for radiation exposure), and only the initial exposure spectrum at each position was used during overall data analysis. Data represent the average of 6 scans.

XAS spectra were processed and analyzed using the EXAFSPAK program suite written for Macintosh OSX (EXAFSPAK; http://www-ssrl.slac.stanford.edu/ $\sim$ george/exafspak/exafs.htm, 2001), integrated with the Feff v8 software ${ }^{34}$ for theoretical model generation. EXAFS fitting analysis was performed on raw/ unfiltered data. Single scattering models were calculated for oxygen, nitrogen, sulfur, copper, and carbon coordination to simulate possible copper ligand environments, with values for the scale factors $(\mathrm{Sc})$ and $\mathrm{E}_{0}$ calibrated by previous fittings of characterized crystallographic copper model compounds ${ }^{35}$. Standard criteria for judging the best-fit EXAFS simulations included reasonable Debye-Waller factors $\left(\sigma^{2}<0.006 \AA^{2}\right)^{36}$, the spectral resolution calculated based on the energy range extent of usable data ${ }^{37}$, and the lowest mean square deviation between data and fit corrected for the number of degrees of freedom $\left(F^{3}\right)^{37}$. During the standard criteria simulations, only the bond length and Debye-Waller factor were allowed to vary for each ligand environment. A scale factor of 0.95 and $\mathrm{E}_{0}$ values of $-12,-14$, and -16 were used for $\mathrm{Cu}-\mathrm{C} / \mathrm{N} / \mathrm{O}, \mathrm{Cu}-\mathrm{S}$, and $\mathrm{Cu}-\mathrm{Cu}$ theoretical model calibration; these values were obtained from simulating authentic $\mathrm{Cu}-\mathrm{Cu}$ models ${ }^{35}$. Simulations applying a formal but static $\mathrm{Cu}-\mathrm{Cu}$ interaction were also tested in an attempt to deconvolute potential $\mathrm{Cu}-\mathrm{Cu}$ scattering in the $\mathrm{Cu}$ EXAFS for each sample set. Fits using the static $\mathrm{Cu}-\mathrm{Cu}$ ligand environment followed the strategy outlined by Blackburn et al. ${ }^{20}$ which was applied to systems in which $\mathrm{Cu}-\mathrm{S}$ and $\mathrm{Cu}-\mathrm{Cu}$ interactions were nonresolvable, as is the case in these data. Static $\mathrm{Cu}-\mathrm{Cu}$ fits held the $\mathrm{Cu}$ ligand parameters constant, manually stepping through the $\mathrm{Cu}-\mathrm{Cu}$ bond length, but not allowing the bond length or Debye-Waller factor for this ligand environment to vary; however, the bond length and Debye-Waller factor in each additional ligand environment was allowed to vary during these static $\mathrm{Cu}-\mathrm{Cu}$ simulations (Supplementary Table 1).

Crystallization and structure determination. Crystals of the copper-bound monomeric species were obtained using $3 \mathrm{mg} \mathrm{mL}^{-1}$ protein in the Classics Suite (Qiagen) condition $\mathrm{H} 1$ (0.1 M ammonium acetate, $\mathrm{pH}$ 4.6, 0.2 M ammonium sulfate, $25 \%(\mathrm{w} / \mathrm{v})$ polyethylene glycol (PEG) 4000). Crystallization conditions were further optimized, and the crystal used for data collection was obtained from sitting drop screens with $0.1 \mathrm{M}$ sodium acetate, $\mathrm{pH} 4.6,0.2 \mathrm{M}$ ammonium sulfate, $18 \%$ PEG 4000 as the precipitant. Prior to data collection, the crystal was transferred to a cryoprotectant solution consisting of the precipitant supplemented with $10 \%$ ethylene glycol for $5 \mathrm{~s}$ and then submerged in liquid nitrogen. Data were collected at $100 \mathrm{~K}$ at a wavelength of $1.377 \AA$ using a Pilatus detector at GM/CA beamline 23 ID-B at the Advanced Photon Source (APS) at Argonne National Laboratory. The crystals belong to space group $P 3_{2} 21$ with two PmoD monomers in the asymmetric unit. The data were processed using HKL2000 to $1.9 \AA$ resolution (Supplementary Table 2). The structure was solved using the SAD method with phenix.autosol ${ }^{38}$, yielding a Bayes CC of 56.6 and a FOM (figure of merit) of 45.6 , indicating that the solution was likely correct. Phenix.autobuild ${ }^{38}$ was used to obtain an initial model that included 245 residues in two protein chains and had an $R / R_{\text {free }}$ of $24.7 \% / 27.0 \%$. This model was improved through iterative rounds of model building using $\operatorname{Coot}^{39}$ and refinement using phenix.refine ${ }^{38}$ resulting in a final $R / R_{\text {free }}$ value of $17.2 \% / 20.9 \%$ (Supplementary Table 2 ). The final model includes 253 residues (amino acids 38-163 in chain A and amino acids 37-163 in chain $\mathrm{B}), 1 \mathrm{Cu}$ ion, 126 water molecules, and a single sulfate ion. The Ramachandran plot indicates that $99.2 \%$ of residues are in favored regions with the remaining $0.8 \%$ in allowed regions. The Molprobity ${ }^{40}$ score is 1.29 (99th percentile).

Construction of a $\triangle p m o D$ strain of Methylosinus trichosporium OB3b. The Methylosinus trichosporium OB3b $\triangle p m o D$ mutant was generated by chromosomal gene disruption into wild-type Methylosinus trichosporium OB3b (a gift from John Lipscomb) using methods described previously ${ }^{41}$. Briefly, a gentamicin resistance gene $\left(\mathrm{gen}^{R}\right)$ was inserted in the middle of $\mathrm{PmoD}_{\text {MettrDRAFT_0381 }}$ via homologous recombination. Primers targeting regions $600 \mathrm{bp}$ upstream and $600 \mathrm{bp}$ downstream from the center of the pmoD gene were used to amplify the DNA flanking the inserted $g e n^{R}$. The gentamicin resistance cassette was amplified from vector pFBOH-LIC using primers listed in Supplementary Table 5. The PCR products were assembled into $\mathrm{pK} 18 \mathrm{mobsacB} \_$p15a $\mathrm{a}^{41}$ using Gibson assembly with primers listed in Supplementary Table 5 and transformed into Escherichia coli S17-1 ATCC 47055 to produce plasmid pSYR16. This plasmid was then introduced into Methylosinus trichosporium OB3b via conjugation with E. coli S17-1 cells transformed with pSYR16 on NMS mating agar plates $\left.(0 \mu \mathrm{M} \mathrm{CuSO})_{4}\right)$. After 2 days, mated cells were plated on NMS selection agar plates $\left(0 \mu \mathrm{M} \mathrm{CuSO}_{4}\right)$ containing kanamycin $\left(25 \mu \mathrm{g} \mathrm{mL}^{-1}\right)$ and nalidixic acid $\left(10 \mu \mathrm{g} \mathrm{mL}^{-1}\right)$. Single colonies from selection plates were picked and streaked onto NMS counter selection plates $(0 \mu \mathrm{M}$ $\left.\mathrm{CuSO}_{4}\right)$ containing $2.5 \%$ sucrose and gentamicin $\left(10 \mu \mathrm{gL}^{-1}\right)$. Single colonies from counter selection plates were then plated and maintained on NMS agar plates $\left(0 \mu \mathrm{M} \mathrm{CuSO}_{4}\right)$ containing gentamicin $\left(10 \mu \mathrm{g} \mathrm{mL}^{-1}\right)$. Genotyping and sequencing were performed to confirm generation of the mutant using the primers listed in 
Supplementary Table 542. Cells on NMS agar plates were incubated in GasPak plate incubation chambers (BD) at $30^{\circ} \mathrm{C}$ and were subjected daily to vacuum and gas-exchange cycles with gas at a 1:1 methane-to-air ratio and $1 \mathrm{~L} \mathrm{~min}^{-1}$ for $3 \mathrm{~min}$.

\section{Phenotype analysis of Methylosinus trichosporium OB3b strains. Wild-type} Methylosinus trichosporium $\mathrm{OB} 3 \mathrm{~b}$ and the $\triangle p m o D$ strain were cultivated as $50 \mathrm{ml}$ cultures in $250 \mathrm{~mL}$ flasks in NMS medium $\left(10 \mathrm{mM} \mathrm{NaNO}_{3}, 1 \mathrm{mM} \mathrm{K}_{2} \mathrm{SO}_{4}, 150 \mu \mathrm{M}\right.$ $\mathrm{MgSO}_{4}$, and $50 \mu \mathrm{M} \mathrm{CaCl}$, buffered with $3.5 \mathrm{mM}$ phosphate buffer, $\mathrm{pH}$ 6.8) supplemented with trace metals solution $\left(40 \mu \mathrm{M} \mathrm{FeSO}_{4}, 1.6 \mu \mathrm{M} \mathrm{ZnSO}_{4}, 1 \mu \mathrm{M} \mathrm{H}_{3} \mathrm{BO}_{3}, 0.8 \mu \mathrm{M}\right.$ $\mathrm{MnCl}_{2}, 0.5 \mu \mathrm{M} \mathrm{KI}, 0.2 \mu \mathrm{M} \mathrm{Na}_{2} \mathrm{MoO}_{4}$, and $0.2 \mu \mathrm{M} \mathrm{CoCl}_{2}$ ) at $30^{\circ} \mathrm{C}$ shaking at $300 \mathrm{rpm}$. The cultures were sealed with gas-tight rubber septa and fed daily with a 1:3 air/ methane mixture ${ }^{42}$. For copper-replete growths, the medium was supplemented with $10 \mu \mathrm{M} \mathrm{CuSO}_{4}$, and for $\triangle p m o D$ Methylosinus trichosporium OB3b, $5 \mu \mathrm{g} \mathrm{mL}{ }^{-1}$ gentamicin was also included in the growth medium. Growth was monitored daily by withdrawing $1 \mathrm{~mL}$ aliquots and measuring the optical density of the cultures at $600 \mathrm{~nm}$. After a week, phenotypes were analyzed using the naphthalene assay to assess sMMO activity. A saturating amount of naphthalene was added to $1 \mathrm{~mL}$ cell culture, followed by incubation with agitation at $30^{\circ} \mathrm{C}$ for $1 \mathrm{~h}$. sMMO activity was assessed qualitatively by the observation of a color change upon addition of $100 \mu \mathrm{L} 1 \%$ solution of Fast Blue B salt (Sigma) to each reaction. The optical spectra of the spent media were analyzed for the presence of apo Mbn by the presence of distinct absorbance features at 345 and 390 $\mathrm{nm}$. One milliliter of culture was centrifuged at $8000 \times g$ for $10 \mathrm{~min}$ at room temperature and the ultraviolet (UV)-visible light spectrum of the supernatant was measured using an Agilent $8453 \mathrm{UV}$-visible spectrophotometer ${ }^{10}$. To account for growth variability between cultures, the samples for both the naphthalene assay and Mbn assay were adjusted to the same optical density in NMS medium. Cell lysates were prepared and analyzed using sodium dodecyl sulfate-polyacrylamide gel electrophoresis (SDSPAGE) as follows. A $50 \mathrm{mg}$ cell pellet was resuspended in $85 \mu \mathrm{L}$ buffer $(250 \mathrm{mM} \mathrm{NaCl}$, $25 \mathrm{mM}$ PIPES, pH 7.0). Cells were lysed by the addition of $200 \mu \mathrm{L}$ Bacterial Protein Extraction Reagent (B-PER) (Thermo Fisher Scientific) supplemented with $350 \mu \mathrm{g} \mathrm{mL}$ ${ }^{-1}$ lysozyme, $35 \mu \mathrm{g} \mathrm{mL}^{-1}$ DNase I, and $2 \mu \mathrm{L}$ of a $25 \times$ stock solution of cOmplete EDTA-free Protease Inhibitor Cocktail (Roche). After nutation at $4{ }^{\circ} \mathrm{C}$ for $30 \mathrm{~min}$, the solution was centrifuged for $25 \mathrm{~min}$ at $20,000 \times g$ at $4{ }^{\circ} \mathrm{C}, 4 \times$ SDS loading dye was added to the clarified lysate (supernatant), and the sample was run on a 15\% SDS-PAGE gel.

Time-dependent copper-responsive $\mathrm{QPCR}$ analysis of pmoD genes. All timedependent copper-responsive $\mathrm{qPCR}$ experiments were performed in wild-type Methylosinus trichosporium OB3b. For these experiments, as in previous studies ${ }^{10,43}$, Methylosinus trichosporium OB3b cultures were grown in nitric acidwashed spinner flasks to minimize copper concentrations. Cells were grown in NMS medium buffered with $3.5 \mathrm{mM}$ phosphate buffer, $\mathrm{pH} 6.8$, and amended with trace metals at a final concentration of $50 \mu \mathrm{M} \mathrm{CuSO}_{4}, 40 \mu \mathrm{M} \mathrm{FeSO}{ }_{4}, 1.6 \mu \mathrm{M} \mathrm{ZnSO}_{4}$, $1 \mu \mathrm{M} \mathrm{H}_{3} \mathrm{BO}_{3}, 0.8 \mu \mathrm{M} \mathrm{MnCl}, 0.5 \mu \mathrm{M} \mathrm{KI}, 0.2 \mu \mathrm{M} \mathrm{Na}_{2} \mathrm{MoO}_{4}$, and $0.2 \mu \mathrm{M} \mathrm{CoCl}_{2}$. Cultures were stirred at $200 \mathrm{rpm}$ and sparged continuously with a 1:3 methane/air mixture. Once cultures achieved logarithmic growth $\left(\mathrm{A}_{600}=0.6-1.0\right)$, cells were assayed for the production of Mbn and sMMO as proxies for copper starvation. The presence of Mbn was confirmed via absorbance spectroscopy of clarified spent medium and the production of sMMO was confirmed via the colorimetric naphthalene assay.

Once cells achieved logarithmic phase growth and copper starvation was confirmed, time-course experiments were initiated. Cells were harvested prior to the addition of $\mathrm{CuSO}_{4}$ to a final concentration of $12.5 \mu \mathrm{M}$, as well as at three subsequent timepoints $(15 \mathrm{~min}, 5 \mathrm{~h}$, and $24 \mathrm{~h}$ ). All experiments were repeated with three distinct biological replicates. At each timepoint, harvested cells were re-analyzed for Mbn production and sMMO production as well as used for RNA isolation.

All experiments involving RNA used RNase-free reagents and supplies. At each timepoint, culture volumes containing approximately $3 \times 10^{9}$ cells were removed from the harvested cells and added to an ice-cold stop solution containing 5\% phenol and $95 \% \mathrm{EtOH}$, for a final ratio of 10:1.25 cell culture to stop solution. The cells were then centrifuged at $6000 \times g$ for $20 \mathrm{~min}$ at $4{ }^{\circ} \mathrm{C}$, and the resulting pellets were resuspended in $0.6 \mathrm{~mL}$ TE buffer, supplemented with $20 \mathrm{mg}$ lysozyme (Sigma) and $100 \mu \mathrm{L}$ proteinase $\mathrm{K}$ (Qiagen.) The resuspended cells were incubated for 30 min at room temperature on a rocker. After this incubation step, $5 \mathrm{~mL}$ of Qiazol (Qiagen) heated to $65^{\circ} \mathrm{C}$ was added to each reaction, and RNA purification was performed using an RNeasy Midi kit (Qiagen), following the protocol described in the RNeasy Lipid Handbook. This initial process included an on-column DNase treatment step. All RNA was eluted in RNase-free water and underwent preliminary quantification using a Nanodrop (Thermo). Any remaining genomic DNA was removed using a Turbo DNAfree kit (Life Technologies). The purified RNA was further processed using an isopropanol/ethanol precipitation step and was resuspended in $20 \mu \mathrm{L}$ RNase-free $\mathrm{H}_{2} \mathrm{O}$ (Life Technologies). The final RNA concentrations were initially determined using a Nanodrop 1000 (Thermo), but these concentrations were validated using a BioAnalyzer (Agilent), which also yielded RNA integrity numbers for all samples. A SuperScript VILO complementary DNA (cDNA) synthesis kit using random hexamer primers (Life Technologies) was used to synthesize cDNA from $1 \mu \mathrm{g}$ input RNA.

Some primers used in these experiments had been validated previously ${ }^{10}$, including those for the reference genes and for components of the main mmo and pmo operons; new primers were validated using the same process. In short, primers were designed using the IDT PrimerQuest tool using constraints including an amplicon length between 70 and $150 \mathrm{bp}$, no possible products in the genome with fewer than 5 mismatches and 1-2 gaps (as identified using the e-PCR tool (NCBI)), $60^{\circ} \mathrm{C} \leq T_{\mathrm{m}} \leq 64^{\circ} \mathrm{C}, \Delta G_{\text {homodimer }} \geq-7.5$, and $\Delta G_{\text {hairpin }} \geq-3$. qPCR reactions were carried out in white 384-well PCR plates (Bio-Rad), and each reaction contained $1.2 \mu \mathrm{L}$ SYBR GreenER Express Universal Master Mix (Life Technologies) and 1.2 $\mu \mathrm{L}$ containing varying amounts of cDNA or RNA (1 ng in standard reactions, fourfold dilutions from $2 \mathrm{ng}$ to $488 \mathrm{fg}$ in primer efficiency reactions), water, and 90 $\mathrm{nL}$ pooled forward and reverse primers $(5 \mu \mathrm{M}$ each). Each reaction was run with three technical replicates, and no-template controls and no-reverse-transcriptase controls were also included for every primer/sample. Once prepared, qPCR reactions were incubated at $4{ }^{\circ} \mathrm{C}$ for $1 \mathrm{~h}$, centrifuged briefly, and then loaded on a CFX384 (Bio-Rad) thermocycler.

qPCR reactions required an initial 2 min UDG (uracil-DNA glycosylase) inactivation step at $50^{\circ} \mathrm{C}$; this step was followed by a 2 min heating step at $95^{\circ} \mathrm{C}$. These steps were followed by 40 cycles at $95^{\circ} \mathrm{C}$ for $15 \mathrm{~s}$ and $60^{\circ} \mathrm{C}$ for $1 \mathrm{~m}$; plate reading occurred during the combined annealing and extension steps. After the completion of 40 cycles, samples were allowed to anneal at $50^{\circ} \mathrm{C}$ for $1 \mathrm{~min}$, and melt curves were then obtained by performing a $5 \mathrm{~s}$ plate-reading step at $0.5^{\circ} \mathrm{C}$ intervals from $50^{\circ} \mathrm{C}$ to $95^{\circ} \mathrm{C}$. Initial Cq values were determined in the Bio-Rad CFX Manager software using regression for each trace. Wells with no Cq value (where replicates had Cq values), a Cq value 10 greater or less than the other technical replicates, or with a melting curve not corresponding to the melting curve peak of the correct product were removed from consideration. The size of all qPCR products and the specificity of all qPCR reactions were confirmed by loading $5 \mu \mathrm{L}$ reactions onto a $4 \%$ NuSieve 3:1 agarose gel (Lonza) in TBE (Supplementary Fig. 5a).

While initial data screening for primer efficiency and gene expression levels were both analyzed in CFX Manager (Bio-Rad), further analysis was performed in

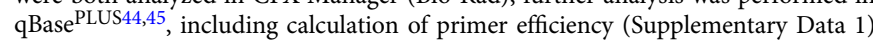
and calculation of normalized relative quantity (NRQ) values for all genes (Supplementary Fig. 5), along with additional statistical analyses (Supplementary Data 1). Hierarchical clustering of $\log _{10}$-transformed NRQ data was performed using Cluster $3.0^{46}$, and these data were used to generate dendrograms and heatmaps in JavaTreeView ${ }^{47}$

Proteomics analysis. Membrane-bound pMMO samples from Methylocystis sp. strain Rockwell (ATCC), Methylococcus capsulatus (Bath) (ATCC), Methylomicrobium alcaliphilum 20Z (a gift from Marina Kalyuzhnaya), and Methylomicrobium buryatense 5GB1C (a gift from Mary Lidstrom) were prepared from cells grown in copper-replete medium. For Methylocystis sp. strain Rockwell, as in previous studies ${ }^{48}$, the growth medium consisted of an adapted NMS-based salt solution consisting of $0.08 \% \mathrm{w} / \mathrm{v} / \mathrm{KNO}_{3}, 0.02 \% \mathrm{w} / \mathrm{v} \mathrm{K}_{2} \mathrm{SO}_{4}, 0.003 \% \mathrm{w} / \mathrm{v}$ $\mathrm{MgSO}_{4} \cdot 7 \mathrm{H}_{2} \mathrm{O}$, and $0.00007 \% \mathrm{w} / \mathrm{v} \mathrm{CaCl} \cdot 2 \mathrm{H}_{2} \mathrm{O}$ buffered with $3.9 \mathrm{mM}$ phosphate buffer, $\mathrm{pH} 7.0$, and supplemented by a trace metal solution consisting of $50 \mu \mathrm{M}$ $\mathrm{CuSO}_{4}, 40 \mu \mathrm{M} \mathrm{FeSO}_{4}, 2 \mu \mathrm{M} \mathrm{ZnSO}_{4}, 2 \mu \mathrm{M} \mathrm{H}_{3} \mathrm{BO}_{3}, 1.6 \mu \mathrm{M} \mathrm{MnCl}_{2}, 1 \mu \mathrm{M} \mathrm{KI}, 0.4 \mu \mathrm{M}$ $\mathrm{Na}_{2} \mathrm{MoO}_{4}$, and $0.4 \mu \mathrm{M} \mathrm{CoCl}_{2}$. Cells were grown in $12 \mathrm{~L}$ fermentations at $30^{\circ} \mathrm{C}$ and $300 \mathrm{rpm}$ with gas sparging at a 3:1 air-to-methane ratio. Once an $\mathrm{A}_{600}=5.0-8.0$ was reached, cells were harvested by centrifugation at $5-7000 \times g$ for $10 \mathrm{~min}$. Cells were washed 1-3 times with a buffer consisting of $25 \mathrm{mM}$ PIPES, $\mathrm{pH} 6.8$, before freezing in liquid nitrogen. For Methylococcus capsulatus (Bath), as in previous growths ${ }^{48}$, the growth medium consisted of NMS solution which contains $0.2 \% \mathrm{w} / \mathrm{v}$ $\mathrm{KNO}_{3}, 0.1 \% \mathrm{w} / \mathrm{v} \mathrm{MgSO}_{4} \cdot 7 \mathrm{H}_{2} \mathrm{O}$, and $0.001 \% \mathrm{CaCl}_{2} \cdot 7 \mathrm{H}_{2} \mathrm{O}$, along with $3.9 \mathrm{mM}$ phosphate buffer, $\mathrm{pH}$ 6.8. This medium was supplemented with trace metals, including $50 \mu \mathrm{M} \mathrm{CuSO}_{4}, 80 \mu \mathrm{M} \mathrm{NaFe}(\mathrm{III}) \mathrm{EDTA}, 1 \mu \mathrm{M} \mathrm{Na}_{2} \mathrm{MoO}_{4}$, and a trace metal solution composed of $0.6 \mu \mathrm{M} \mathrm{Na} \mathrm{Na}_{2} \bullet$ EDTA, $0.4 \mu \mathrm{M} \mathrm{FeSO} \mathrm{F}_{4} \cdot 7 \mathrm{H}_{2} \mathrm{O}, 0.02 \mu \mathrm{M}$ $\mathrm{ZnSO}_{4} \cdot 7 \mathrm{H}_{2} \mathrm{O}, 0.008 \mu \mathrm{M} \mathrm{MnCl} \cdot 4 \mathrm{H}_{2} \mathrm{O}, 0.24 \mu \mathrm{M} \mathrm{H}_{3} \mathrm{BO}_{3}, 0.042 \mu \mathrm{M} \mathrm{CoCl} \cdot 6 \mathrm{H}_{2} \mathrm{O}$, $0.004 \mu \mathrm{M} \mathrm{NiCl} \mathrm{N}_{2} \bullet 6 \mathrm{H}_{2} \mathrm{O}$, and $0.006 \mu \mathrm{M} \mathrm{Na}_{2} \mathrm{MoO}_{4} \bullet 2 \mathrm{H}_{2} \mathrm{O}$. Cells were grown in $12 \mathrm{~L}$ fermentations at $300 \mathrm{rpm}$ and $45^{\circ} \mathrm{C}$ with gas sparging at a 4:1 air/methane ratio. Cells were harvested as described for Methylocystis sp. Rockwell. As in previous studies ${ }^{49}$, Methylomicrobium alcaliphilum $20 \mathrm{Z}$ was grown in modified NMS (NMSA) medium amended with $2.3 \mathrm{mM}$ phosphate buffer at pH 7.2, $50 \mathrm{mM}$ carbonate buffer $\mathrm{pH} 9.5,500 \mathrm{mM} \mathrm{NaCl}, 40 \mu \mathrm{M} \mathrm{CuSO}$ and a trace metal solution containing $0.3 \mu \mathrm{M} \mathrm{Na}_{2} \bullet$ EDTA, $0.2 \mu \mathrm{M} \mathrm{FeSO}_{4} \cdot 7 \mathrm{H}_{2} \mathrm{O}, 0.009 \mu \mathrm{M} \mathrm{ZnSO}{ }_{4} \cdot 7 \mathrm{H}_{2} \mathrm{O}$, $0.004 \mu \mathrm{M} \mathrm{MnCl}{ }_{2} \bullet 4 \mathrm{H}_{2} \mathrm{O}, 0.1 \mu \mathrm{M} \mathrm{H}_{3} \mathrm{BO}_{3}, 0.02 \mu \mathrm{M} \mathrm{CoCl}_{2} \bullet 6 \mathrm{H}_{2} \mathrm{O}, 0.002 \mu \mathrm{M}$ $\mathrm{NiCl}_{2} \cdot 6 \mathrm{H}_{2} \mathrm{O}$, and $0.003 \mu \mathrm{M} \mathrm{Na} \mathrm{MoO}_{4} \cdot 2 \mathrm{H}_{2} \mathrm{O}$. Cells were grown in $12 \mathrm{~L}$ fermentation volumes as described for Methylocystis sp. Rockwell. Cells were harvested at $\mathrm{A}_{600}$ of 8-10, centrifuged at $8000 \times g$ for $30 \mathrm{~min}$, and flash frozen in liquid nitrogen. As in previous studies ${ }^{50,51}$, Methylomicrobium buryatense $5 \mathrm{~GB} 1 \mathrm{C}$ was grown in modified NMSA medium amended with $2.3 \mathrm{mM}$ phosphate buffer, $\mathrm{pH} 6.8,50 \mathrm{mM}$ carbonate buffer, $\mathrm{pH} 9.5,130 \mathrm{mM} \mathrm{NaCl}, 40 \mu \mathrm{M} \mathrm{CuSO}_{4}$, and a trace metals solution including $5.4 \mu \mathrm{M} \mathrm{Na}_{2} \bullet \mathrm{EDTA}_{1}, 14.4 \mu \mathrm{M} \mathrm{FeSO}_{4} \bullet 7 \mathrm{H}_{2} \mathrm{O}, 5.5 \mu \mathrm{M} \mathrm{ZnSO}{ }_{4} \bullet 7 \mathrm{H}_{2} \mathrm{O}, 0.3 \mu \mathrm{M}$ $\mathrm{MnCl}_{2} \bullet 4 \mathrm{H}_{2} \mathrm{O}, 1 \mu \mathrm{M} \mathrm{H}_{3} \mathrm{BO}_{3}, 1.7 \mu \mathrm{M} \mathrm{CoCl}_{2} \bullet 6 \mathrm{H}_{2} \mathrm{O}, 0.2 \mu \mathrm{M} \mathrm{NiCl}_{2} \bullet 6 \mathrm{H}_{2} \mathrm{O}$, and $0.4 \mu \mathrm{M}$ $\mathrm{Na}_{2} \mathrm{MoO}_{4} \bullet 2 \mathrm{H}_{2} \mathrm{O}$. Growth and harvest were performed as described for Methylomicrobium alcaliphilum $20 \mathrm{Z}$.

To purify pMMO $48,51,52$, frozen cells were thawed in a lysis buffer consisting of $25 \mathrm{mM}$ PIPES, pH 7.2 and $250 \mathrm{mM} \mathrm{NaCl}$, except for Methylomicrobium alcaliphilum $20 \mathrm{Z}$ which required an alternate lysis buffer consisting of $25 \mathrm{mM}$ PIPES, pH 7.2 and $500 \mathrm{mM} \mathrm{NaCl}$. Cells were lysed via sonication, and cell debris was removed via centrifugation at $12,000 \times g$ for $1 \mathrm{~h}$ at $4^{\circ} \mathrm{C}$. The supernatant was harvested, and membranes were pelleted at $100,000 \times g$ for $1 \mathrm{~h}$ at $4^{\circ} \mathrm{C}$ and flash frozen in liquid nitrogen. pMMO was solubilized from the membrane using $1.2 \mathrm{mg}$ 
$n$-dodecyl- $\beta$-D-maltopyranoside (DDM) (Anatrace) per $1 \mathrm{mg}$ of crude protein for $1 \mathrm{~h}$ at $4{ }^{\circ} \mathrm{C}$. The membrane was pelleted via centrifugation at $100,000 \times g$ for $30 \mathrm{~min}$ at $4{ }^{\circ} \mathrm{C}$, and the supernatant containing the detergent-bound, solubilized pMMO was collected for further purification. Methylococcus capsulatus (Bath) pMMO was purified using a Superdex 200 size exclusion chromatography column (GE Healthcare) equilibrated with $25 \mathrm{mM}$ PIPES, pH 7.3, $250 \mathrm{mM} \mathrm{NaCl}$, and $0.02 \%$ DDM. pMMOs from Methylocystis sp. strain Rockwell, Methylomicrobium alcaliphilum 20Z, and Methylomicrobium buryatense 5GB1C were purified using a $15 \mathrm{Q}$ anion exchange chromatography column (GE Healthcare) with a $50-800 \mathrm{mM}$ $\mathrm{NaCl}$ gradient in $25 \mathrm{mM}$ PIPES, $\mathrm{pH}$ 7.3, $0.02 \%$ DDM. pMMO-containing fractions were concentrated and buffer exchanged into $25 \mathrm{mM}$ PIPES, pH 7.3, $250 \mathrm{mM}$ $\mathrm{NaCl}, 0.02 \% \mathrm{DDM}$ using an Amicon centrifugal concentrator (Millipore) with a $100 \mathrm{kDa}$ MWCO.

Proteins were separated via reverse-phase HPLC on an Agilent 1100 HPLC using a 214TP54 analytical C4 column (Grace Vydac: $5 \mu \mathrm{m}, 250 \times 4.6 \mathrm{~mm}$ i.d.). Approximately $100 \mu \mathrm{L}$ pMMO (at a concentration of $100 \mu \mathrm{M}$ ) was loaded onto the column, and the protein was eluted using a gradient from $100 \%$ A $(63.75 \%$ formic acid, $10 \%$ acetonitrile, $5 \% i$ - $\mathrm{PrOH}$ ) to $100 \% \mathrm{~B}$ ( $70 \%$ formic acid, $30 \% i$-PrOH) over $60 \mathrm{~min}$ at $0.5 \mathrm{~mL} \mathrm{~min}^{-1}$. Then, $100 \mu \mathrm{L}$ of approximately $100 \mu \mathrm{M}$ protein (concentration calculated per pMMO protomer) was injected with each run. Elution fractions were collected every $0.25 \mathrm{~mL}$. Samples were then diluted 1:8 with water and digested with $2 \mu \mathrm{g}$ pepsin at $37^{\circ} \mathrm{C}$ overnight (Promega). Samples were heated at $95^{\circ} \mathrm{C}$ for $10 \mathrm{~min}$ to inactivate pepsin.

Copper-replete Methylosinus trichosporium OB3b was grown as described above. Cells were harvested near the late stages of logarithmic growth (an optical density at $600 \mathrm{~nm}$ of $\sim 1$ ). Whole cell lysate from Methylosinus trichosporium OB3b cells was obtained using an SDS lysis buffer containing 4\% SDS, $100 \mathrm{mM}$ HEPES, $\mathrm{pH} 7.2,10 \mathrm{mM}$ DTT, and EDTA-free cOmplete protease inhibitors (Roche) at a final volume of 1 tablet per $50 \mathrm{~mL}$ lysis buffer. Proteins were precipitated with 8 volumes of cold acetone and one volume of trichloroacetic acid overnight at $-20^{\circ}$ C. After washing the pellet with ice-cold acetone, resulting proteins were resuspended in $50 \mu \mathrm{L}$ deionized $8 \mathrm{M}$ urea in $100 \mathrm{mM}$ ammonium bicarbonate, $\mathrm{pH}$ 7.8 , reduced with $10 \mathrm{mM}$ DTT at $50^{\circ} \mathrm{C}$ for $30 \mathrm{~min}$, and cysteines were alkylated with $35 \mathrm{mM}$ iodoacetamide in the dark for $30 \mathrm{~min}$. The solution was then diluted to $<2 \mathrm{M}$ urea (final concentration) and $1 \mu \mathrm{g}$ porcine trypsin (Thermo) was added prior to overnight incubation at $37^{\circ} \mathrm{C}$ with shaking.

For both samples, the resulting peptides were desalted using solid phase extraction on a Pierce C18 Spin column and eluted in $80 \mu \mathrm{L}$ of $80 \%$ acetonitrile in $0.1 \%$ formic acid. After lyophilization, peptides were reconstituted with $5 \%$ acetonitrile in $0.1 \%$ formic acid and injected onto a trap column $(150 \mu \mathrm{m}$ i.d. $\times 3$ $\mathrm{cm})$ coupled with a nanobore analytical column $(75 \mu \mathrm{m}$ i.d. $\times 15 \mathrm{~cm}$, both ReproSil C18aq, $3 \mu \mathrm{m})$. Samples were separated using a linear gradient of solvent A $(95 \%$ water, $5 \%$ acetonitrile, $0.1 \%$ formic acid) and solvent B (5\% water, $95 \%$ acetonitrile, $0.1 \%$ formic acid) over $60 \mathrm{~min}$. Mass spectrometry (MS) data were obtained on a Velos Orbitrap Elite (Thermo) mass spectrometer. Data were searched using Mascot (Matrix Science) 2.5 against the SwissProt database and results were reported at $1 \%$ false discovery rate in Scaffold 4.5 (Proteome Software).

Bioinformatics analyses. There are no pre-existing protein families to which PmoD sequences belong, and pmoD genes are commonly unannotated or are annotated solely as a hypothetical membrane protein. Thus, the $\mathrm{PmoD}_{\text {Mettr- }}$ DRAFT_ 0381 sequence was used as an initial seed for a protein BLAST search against the JGI/IMG genome database. The most divergent result was used as the seed for a second BLAST round, and this was repeated until no additional PmoD sequences were obtained. The amino acid sequences of these genes and their associated metadata were downloaded on 10 October 2017

All putative PmoD sequences were aligned via MAFFT (L-INS-I mode) ${ }^{53}$. After alignment, sequences were trimmed. Truncated sequences with less than 150 amino acids (aa) were removed from the dataset, as were sequences with more than 250 aa that did not contain the two characteristic cysteines along with an $\mathrm{N}$ terminal signal peptide sequence and a C-terminal transmembrane sequence. The trimmed dataset included 860 putative PmoD sequences, of which $98.5 \%$ were found in species encoding an enzyme homologous to pMMO and AMO. The metadata file was updated to remove trimmed sequences (Supplementary Data 2), and the trimmed dataset (Supplementary Data 3) was realigned via MAFFT and used to establish a HMM (Supplementary Data 4) via HMMER 3.154. PmoD subgroups were aligned against the profile HMM using HMMalign (Supplementary Figure 7) to visualize differences in subgroup sequence conservation.

A sequence similarity network was constructed using the EFI-EST tool ${ }^{55}$, with an $E$-value cutoff of 21 and condensation of identical sequences into a single node. The resulting network (Supplementary Data 5) was visualized in Cytoscape 3.5.1 ${ }^{56}$. As in previous studies ${ }^{30}$, additional metadata was added for each gene for visualization within the context of the sequence similarity network. This included genus (from which subgroups of methane- and ammonia-oxidizing bacteria were identified) and conservation of specific residues of interest using the alignment generated via hmmalign. For genome neighborhood analysis, hierarchical clustering of $p m o D$ genes against traits (presence of genes annotated with specific PFAM and TIGRFAM families within 5 genes up- and downstream from pmoDspecific metal binding motifs) was carried out as described previously. The resulting dataset (Supplementary Data 2) was examined to establish 20 main operon groups (Supplementary Figure 8).

To analyze the co-occurrence of specific copper-related genes with CuMMOencoding operons, lists of genomes containing genes corresponding to specific protein families were generated by analyzing all genomes in the JGI/IMG database. The $a / p m o B$ genes (as a proxy for amo/pmo operons) were identified as belonging to the PF04744 family; sMMO-encoding operons were identified as members of the TIGR04550 family which corresponds to $m m o D$ genes, not generally found in nonsMMO soluble diiron monooxygenase operons; $m b n$ operons were identified via BLAST and manually curated using an $E$-value cutoff of $20^{57}$ using the Methylosinus trichosporium OB3b mbnB gene (MettrDRAFT_3422, corrected to remove the unconserved internal stop codon in the published genome $)^{10}$; MopE/ CorA homologs were identified using BLAST (against Methylomicrobium album BG8 corA gene (MetalDRAFT_3218) and Methylococcus capsulatus Bath mopE gene (MCA2589), since the existing profile HMM, which defines family PF11617, matches only a small region of the MopE/CorA sequence and thus lacks specificity beyond the putative metal binding site); csp 1/2 genes were identified as belonging to the TIGR04401 family; csp3 genes were identified as belonging to the PF03860 family or were identified as one of the top 500 BLAST results for Methylosinus trichosporium OB3b csp3 gene (MettrDRAFT_1424), since some csp3 genes more closely related to the Methylosinus trichosporium OB3b gene were not annotated as DUF326 genes (Supplementary Discussion); pmoD genes were identified as described above. Lists of genomes containing each class of gene were extracted from the JGI/IMG gene metadata, and the co-occurrence of genes of various classes in a given genome was quantified.

\section{Data availability}

The coordinates and structure factors for the $\mathrm{PmoD}_{\text {Met49242_1452 structure have been }}$ deposited in the Protein Databank with accession code 6CPD. Other data are available from the corresponding author upon reasonable request.

Received: 2 May 2018 Accepted: 20 September 2018 Published online: 15 October 2018

\section{References}

1. Hanson, R. S. \& Hanson, T. E. Methanotrophic bacteria. Microbiol. Rev. 60, 439-471 (1996).

2. Chai, X. L., Tonjes, D. J. \& Mahajan, D. Methane emissions as energy reservoir: context, scope, causes and mitigation strategies. Prog. Energy Combust. Sci. 56, 33-70 (2016).

3. Sirajuddin, S. \& Rosenzweig, A. C. Enzymatic oxidation of methane. Biochemistry 54, 2283-2294 (2015).

4. Blanksby, S. J. \& Ellison, G. B. Bond dissociation energies of organic molecules. ACC Chem. Res. 36, 255-263 (2003).

5. Lawton, T. J. \& Rosenzweig, A. C. Methane-oxidizing enzymes: an upstream problem in biological gas-to-liquids conversion. J. Am. Chem. Soc. 138, 9327-9340 (2016).

6. Norton, J. M., Alzerreca, J. J., Suwa, Y. \& Klotz, M. G. Diversity of ammonia monooxygenase operon in autotrophic ammonia-oxidizing bacteria. Arch. Microbiol. 177, 139-149 (2002).

7. Heil, J., Vereecken, H. \& Bruggemann, N. A review of chemical reactions of nitrification intermediates and their role in nitrogen cycling and nitrogen trace gas formation in soil. Eur. J. Soil Sci. 67, 23-39 (2016).

8. Arp, D. J. \& Stein, L. Y. Metabolism of inorganic N compounds by ammoniaoxidizing bacteria. Crit. Rev. Biochem. Mol. Biol. 38, 471-495 (2003)

9. Arp, D. J., Chain, P. S. G. \& Klotz, M. G. The impact of genome analyses on our understanding of ammonia-oxidizing bacteria. Annu. Rev. Microbiol. 61, 503-528 (2007).

10. Kenney, G. E., Sadek, M. \& Rosenzweig, A. C. Copper-responsive gene expression in the methanotroph Methylosinus trichosporium OB3b. Metallomics 8, 931-940 (2016).

11. El Sheikh, A. F., Poret-Peterson, A. T. \& Klotz, M. G. Characterization of two new genes, amoR and amoD, in the amo operon of the marine ammonia oxidizer Nitrosococcus oceani ATCC 19707. Appl. Environ. Microbiol. 74, 312-318 (2008)

12. Berube, P. M. \& Stahl, D. A. The divergent $\mathrm{AmoC}_{3}$ subunit of ammonia monooxygenase functions as part of a stress response system in Nitrosomonas europaea. J. Bacteriol. 194, 3448-3456 (2012).

13. Klotz, M. \& Stein, L. in Nitrification (eds Ward, B. B., Arp, D. J. \& Klotz, M. G.) 57-93 (ASM Press, Washington, 2011).

14. Liu, J. et al. Metalloproteins containing cytochrome, iron-sulfur, or copper redox centers. Chem. Rev. 114, 4366-4469 (2014).

15. Beinert, H. Copper A of cytochrome $c$ oxidase, a novel, long-embattled biological electron-transfer site. Eur. J. Biochem. 245, 521-532 (1997). 
16. Gamelin, E. R. et al. Spectroscopy of mixed-valence $\mathrm{Cu}_{\mathrm{A}}$-type centers: ligandfield control of ground-state properties related to electron transfer. J. Am. Chem. Soc. 120, 5246-5263 (1998).

17. Savelieff, M. G. \& Lu, Y. $\mathrm{Cu}_{\mathrm{A}}$ centers and their biosynthetic models in azurin. J. Biol. Inorg. Chem. 15, 461-483 (2010).

18. Kroneck, P. M. H. Walking the seven lines: binuclear copper A in cytochrome $c$ oxidase and nitrous oxide reductase. J. Biol. Inorg. Chem. 23, 27-39 (2018).

19. Hay, M. T. et al. Spectroscopic characterization of an engineered purple $\mathrm{Cu}_{\mathrm{A}}$ center in azurin. Inorg. Chem. 37, 191-198 (1998).

20. Blackburn, N. J. et al. X-ray absorption studies on the mixed-valence and fully reduced forms of the soluble $\mathrm{Cu}_{\mathrm{A}}$ domains of cytochrome $c$ oxidase. J. Am. Chem. Soc. 119, 6135-6143 (1997).

21. Williams, $\mathrm{P}$. A. et al. The $\mathrm{Cu}_{\mathrm{A}}$ domain of Thermus thermophilus $b a_{3}$-type cytochrome $c$ oxidase at $1.6 \AA$ resolution. Nat. Struct. Biol. 6, 509-516 (1999).

22. Brown, $\mathrm{K}$. et al. Revisiting the catalytic CuZ cluster of nitrous oxide $\left(\mathrm{N}_{2} \mathrm{O}\right)$ reductase. Evidence of a bridging inorganic sulfur. J. Biol. Chem. 275, 41133-41136 (2000).

23. Robinson, H. et al. Structural basis of electron transfer modulation in the purple $\mathrm{Cu}_{\mathrm{A}}$ center. Biochemistry 38, 5677-5683 (1999).

24. Kenney, G. E. \& Rosenzweig, A. C. Methanobactins: maintaining copper homeostasis in methanotrophs and beyond. J. Biol. Chem. 293, 4606-4615 (2018).

25. Phelps, P. A., Agarwal, S. K., Speitel, G. E. Jr. \& Georgiou, G. Methylosinus trichosporium $\mathrm{OB} 3 \mathrm{~b}$ mutants having constitutive expression of soluble methane monooxygenase in the presence of high levels of copper. Appl. Environ. Microbiol. 58, 3701-3708 (1992).

26. El Sheikh, A. F. \& Klotz, M. G. Ammonia-dependent differential regulation of the gene cluster that encodes ammonia monooxygenase in Nitrosococcus oceani ATCC 19707. Environ. Microbiol. 10, 3026-3035 (2008).

27. Gu, W. Y. \& Semrau, J. D. Copper and cerium-regulated gene expression in Methylosinus trichosporium OB3b. Appl. Microbiol. Biotechnol. 101, 8499-8516 (2017).

28. Larsen, O. \& Karlsen, O. A. Transcriptomic profiling of Methylococcus capsulatus (Bath) during growth with two different methane monooxygenases. Microbiologyopen 5, 254-267 (2016).

29. Coleman, N. V. et al. Hydrocarbon monooxygenase in Mycobacterium: recombinant expression of a member of the ammonia monooxygenase superfamily. ISME J. 6, 171-182 (2012).

30. Lawton, T. J., Kenney, G. E., Hurley, J. D. \& Rosenzweig, A. C. The CopC family: structural and bioinformatic insights into a diverse group of periplasmic copper binding proteins. Biochemistry 55, 2278-2290 (2016).

31. Peisach, J. \& Blumberg, W. E. Structural implications derived from the analysis of electron paramagnetic resonance spectra of natural and artificial copper proteins. Arch. Biochem. Biophys. 165, 691-708 (1974).

32. Bennett, B. \& Kowalski, J. M. EPR methods for biological Cu(II): L-band CW and NARS. Methods Enzymol. 563, 341-361 (2015).

33. Studier, F. W. Stable expression clones and auto-induction for protein production in E. coli. Methods Mol. Biol. 1091, 17-32 (2014).

34. Ankudinov, A. L. \& Rehr, J. J. Relativistic calculations of spin-dependent Xray absorption spectra. Phys. Rev. B 56, R1712-R1715 (1997).

35. Lieberman, R. L. et al. Characterization of the particulate methane monooxygenase metal centers in multiple redox states by X-ray absorption spectroscopy. Inorg. Chem. 45, 8372-8381 (2006).

36. Cotelesage, J. J., Pushie, M. J., Grochulski, P., Pickering, I. J. \& George, G. N. Metalloprotein active site structure determination: synergy between X-ray absorption spectroscopy and X-ray crystallography. J. Inorg. Biochem. 115, 127-137 (2012).

37. Riggs-Gelasco, P. J., Stemmler, T. L. \& Penner-Hahn, J. E. XAFS of dinuclear metal sites in proteins and model compounds. Coord. Chem. Rev. 144, 245-286 (1995).

38. Adams, P. D. et al. PHENIX: a comprehensive Python-based system for macromolecular structure solution. Acta Cryst D66, 213-221 (2010).

39. Emsley, P. \& Cowtan, K. Coot: model-building tools for molecular graphics. Acta Cryst. D60, 2126-2132 (2004)

40. Chen, V. B. et al. MolProbity: all-atom structure validation for macromolecular crystallography. Acta Cryst. D66, 12-21 (2010).

41. Ro, S. Y. \& Rosenzweig, A. C. Recent advances in the genetic manipulation of Methylosinus trichosporium OB3b. Methods Enzymol. 605, 335-349 (2018).

42. Balasubramanian, R., Kenney, G. E. \& Rosenzweig, A. C. Dual pathways for copper uptake by methanotrophic bacteria. J. Biol. Chem. 286, 37313-37319 (2011).

43. Dassama, L. M., Kenney, G. E., Ro, S. Y., Zielazinski, E. L. \& Rosenzweig, A. C. Methanobactin transport machinery. Proc. Natl. Acad. Sci. USA 113, 13027-13032 (2016)

44. Hellemans, J., Mortier, G., De Paepe, A., Speleman, F. \& Vandesompele, J. qBase relative quantification framework and software for management and automated analysis of real-time quantitative PCR data. Genome Biol. 8, R19 (2007).
45. Vandesompele, J. et al. Accurate normalization of real-time quantitative RTPCR data by geometric averaging of multiple internal control genes. Genome Biol. 3, RESEARCH0034 (2002).

46. Eisen, M. B., Spellman, P. T., Brown, P. O. \& Botstein, D. Cluster analysis and display of genome-wide expression patterns. Proc. Natl. Acad. Sci. USA 95, 14863-14868 (1998).

47. Saldanha, A. J. Java Treeview--extensible visualization of microarray data. Bioinformatics 20, 3246-3248 (2004).

48. Sirajuddin, S. et al. Effects of zinc on particulate methane monooxygenase activity and structure. J. Biol. Chem. 289, 21782-21794 (2014).

49. Ojala, D. S., Beck, D. A. \& Kalyuzhnaya, M. G. Genetic systems for moderately halo(alkali)philic bacteria of the genus Methylomicrobium. Methods Enzymol. 495, 99-118 (2011).

50. Puri, A. W. et al. Genetic tools for the industrially promising methanotroph Methylomicrobium buryatense. Appl. Environ. Microbiol. 81, 1766-1772 (2015).

51. Deng, Y. W., Ro, S. Y. \& Rosenzweig, A. C. Structure and function of the lanthanide-dependent methanol dehydrogenase XoxF from the methanotroph Methylomicrobium buryatense 5GB1C. J. Biol. Inorg. Chem. https://doi.org/ 10.1007/s00775-018-1604-2 (2018).

52. Ro, S. Y. et al. From micelles to bicelles: effect of the membrane on particulate methane monooxygenase activity. J. Biol. Chem. 293, 10457-10465 (2018).

53. Katoh, K. \& Standley, D. M. MAFFT: iterative refinement and additional methods. Methods Mol. Biol. 1079, 131-146 (2014).

54. Finn, R. D., Clements, J. \& Eddy, S. R. HMMER web server: interactive sequence similarity searching. Nucleic Acids Res. 39, W29-W37 (2011).

55. Gerlt, J. A. et al. Enzyme Function Initiative-Enzyme Similarity Tool (EFIEST): a web tool for generating protein sequence similarity networks. Biochim. Biophys. Acta 1854, 1019-1037 (2015).

56. Shannon, P. et al. Cytoscape: a software environment for integrated models of biomolecular interaction networks. Genome Res. 13, 2498-2504 (2003).

57. Kenney, G. E. \& Rosenzweig, A. C. Genome mining for methanobactins. BMC Biol. 11, 17 (2013).

\section{Acknowledgements}

This work was funded by the Department of Energy grant DE-SC0016284 (A.C.R.), National Institutes of Health grants GM118035 (A.C.R.), GM111097 (B.M.H.), DK068139 (T.L.S.), R01AT009143 (N.L.K.) and F32GM119191 (O.S.F.), and American Heart Association grant 14PRE20460104 (G.E.K.). We thank the staff of the GM/CA and LS-CAT beamlines of the Advanced Photon Source, which is a DOE Office of Science User Facility operated for the DOE Office of Science by Argonne National Laboratory under Contract No. DE-AC0206CH11356. Use of the Stanford Synchrotron Radiation Lightsource, SLAC National Accelerator Laboratory, is supported by the U.S. Department of Energy, Office of Science, Office of Basic Energy Sciences under Contract No. DE-AC02-76SF00515. The SSRL Structural Molecular Biology Program is supported by the DOE Office of Biological and Environmental Research, and by the National Institutes of Health, National Institute of General Medical Sciences (including P41GM103393). The contents of this publication are solely the responsibility of the authors and do not necessarily represent the official views of NIGMS or NIH. Steven Almo and Anthony Gizzi at Albert Einstein College of Medicine produced the wild-type $\mathrm{His}_{6}-\mathrm{PmoD}_{\text {Met49242_1452 }}$ soluble domain construct. The Quantitative Bio-element Imaging Center at Northwestern is supported by NASA Ames Research Center NNA06CB93G. The Proteomics Center for Excellence at Northwestern is supported by National Resource for Translational and Developmental Proteomics under NIH grant P41 GM108569 and NCI CCSG P30 CA060553. The Keck Biophysics Facility at Northwestern is supported in part by NCI CCSG P30 CA060553. We thank Laura M. K. Dassama and Thomas J. Lawton for discussions.

\section{Author contributions}

O.S.F., G.E.K., M.O.R., S.Y.R., P.M.T. and A.C.R. designed research; O.S.F., G.E.K., M.O.R., S.Y.R., B.E.L., S.B., P.M.T., V.C.S., C.J.D. and T.L.S. performed research; O.S.F., G.E.K., M.O.R., S.Y.R., B.E.L., S.B., P.M.T., V.C.S., C.J.D. and T.L.S. analyzed data; and O.S.F., M.O.R., G.E.K., S.Y.R., P.M.T., N.L.K., T.L.S., B.M.H. and A.C.R. wrote the paper.

\section{Additional information}

Supplementary Information accompanies this paper at https://doi.org/10.1038/s41467 018-06681-5.

Competing interests: The authors declare no competing interests.

Reprints and permission information is available online at http://npg.nature.com/ reprintsandpermissions/

Publisher's note: Springer Nature remains neutral with regard to jurisdictional claims in published maps and institutional affiliations. 
(c) (i) Open Access This article is licensed under a Creative Commons Attribution 4.0 International License, which permits use, sharing, adaptation, distribution and reproduction in any medium or format, as long as you give appropriate credit to the original author(s) and the source, provide a link to the Creative Commons license, and indicate if changes were made. The images or other third party material in this article are included in the article's Creative Commons license, unless indicated otherwise in a credit line to the material. If material is not included in the article's Creative Commons license and your intended use is not permitted by statutory regulation or exceeds the permitted use, you will need to obtain permission directly from the copyright holder. To view a copy of this license, visit http://creativecommons.org/ licenses/by/4.0/.

(C) The Author(s) 2018 